\title{
Modeling of the molybdenum loss in iron molybdate catalyst pellets for selective oxidation of methanol to formaldehyde
}

Raun, Kristian Viegaard; Johannessen, Jeppe; McCormack, Kaylee; Appel, Charlotte Clausen; Baier, Sina; Thorhauge, Max; Høj, Martin; Jensen, Anker Degn

\section{Published in:}

Chemical Engineering Journal

Link to article, DOI:

10.1016/j.cej.2018.12.142

Publication date:

2019

Document Version

Peer reviewed version

Link back to DTU Orbit

Citation (APA):

Raun, K. V., Johannessen, J., McCormack, K., Appel, C. C., Baier, S., Thorhauge, M., Høj, M., \& Jensen, A. D. (2019). Modeling of the molybdenum loss in iron molybdate catalyst pellets for selective oxidation of methanol to formaldehyde. Chemical Engineering Journal, 361, 1285-1295. https://doi.org/10.1016/j.cej.2018.12.142

\section{General rights}

Copyright and moral rights for the publications made accessible in the public portal are retained by the authors and/or other copyright owners and it is a condition of accessing publications that users recognise and abide by the legal requirements associated with these rights.

- Users may download and print one copy of any publication from the public portal for the purpose of private study or research.

- You may not further distribute the material or use it for any profit-making activity or commercial gain

- You may freely distribute the URL identifying the publication in the public portal 


\title{
Modeling of the Molybdenum Loss in Iron Molybdate Catalyst Pellets for Selective Oxidation of Methanol to Formaldehyde $\uparrow$
}

\author{
$\underline{\text { Kristian Viegaard Raun }}{ }^{1}$, Jeppe Johannessen ${ }^{1}$, Kaylee McCormack ${ }^{1}$, Charlotte Clausen Appel ${ }^{2}$, Sina Baier ${ }^{3}$,

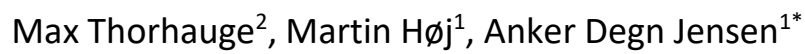 \\ ${ }^{1}$ DTU Chemical Engineering, Technical University of Denmark, 2800 Kgs. Lyngby (Denmark) \\ ${ }^{2}$ Haldor Topsøe A/S, 2800 Kgs. Lyngby (Denmark) \\ ${ }^{3}$ DTU Physics, Technical University of Denmark, 2800 Kgs. Lyngby (Denmark) \\ *aj@kt.dtu.dk
}




\begin{abstract}
The loss of molybdenum from industrial iron molybdate $\left(\mathrm{Fe}_{2}\left(\mathrm{MoO}_{4}\right)_{3}\right)$ catalyst pellets with an excess of molybdenum oxide was studied during selective oxidation of methanol to formaldehyde for up to about 10 days on stream at varying reaction conditions $\left(\mathrm{MeOH}=1.6-4.5 \%, \mathrm{O}_{2}=2.5-10 \%, \mathrm{H}_{2} \mathrm{O}=0-10.2\right.$ vol. $\%$ in $\mathrm{N}_{2}$ and temperature $=250,300$ and $350^{\circ} \mathrm{C}$ ). The changing morphology and the local elemental composition in the pellets were followed for increasing time on stream. Molybdenum was shown to volatilize, leaving a depleted zone starting at the pellet surface and moving inwards with time. For temperatures $\leq 300^{\circ} \mathrm{C}$ only volatilization of the excess $\mathrm{MoO}_{3}$ phase was observed. Increasing concentration of $\mathrm{MeOH}$ and temperature enhanced the rate of volatilization, the oxygen concentration had negligible effect, while increasing the $\mathrm{H}_{2} \mathrm{O}$ concentration decreased the volatilization rate. At $350{ }^{\circ} \mathrm{C}\left(\mathrm{MeOH}=4.5 \%, \mathrm{O}_{2}=10 \%, \mathrm{H}_{2} \mathrm{O}=0 \%\right.$ in $\left.\mathrm{N}_{2}\right) \mathrm{Mo}$ in the $\mathrm{Fe}_{2}\left(\mathrm{MoO}_{4}\right)_{3}$ phase was furthermore volatilized leading to the formation of the reduced ferrous molybdate $\left(\mathrm{FeMoO}_{4}\right)$. A dynamic 1D mathematical model for a single pellet, in which methanol oxidation to formaldehyde and simultaneous volatilization of free $\mathrm{MoO}_{3}$ takes place, was developed. The model parameters were fitted using experimental data of the pellet weight loss while the evolution of the $\mathrm{MoO}_{3}$ depletion layer thickness was used to validate the model. The model describes the data well and additionally predicts that deposition of $\mathrm{MoO}_{3}$ behind the depletion layer front occurs under certain conditions, leading to a $\mathrm{MoO}_{3}$ deposition layer, which was verified by scanning electron microscopy (SEM) combined with energy-dispersive X-ray spectroscopy (EDS). Simulations with the model show that the overall loss of molybdenum is significantly slower for large pellets compared to small pellets, which is a key parameter for the success of the industrial process.
\end{abstract}




\section{Contents}

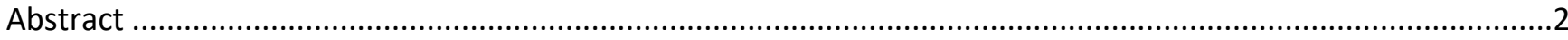

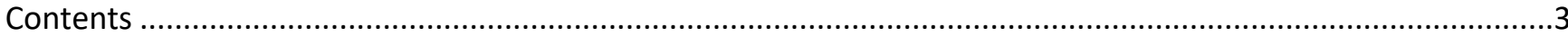

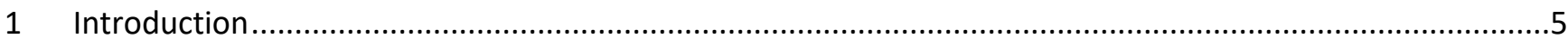

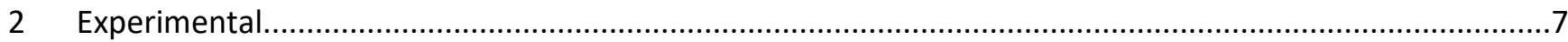

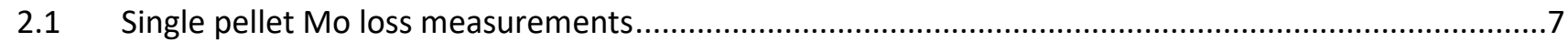

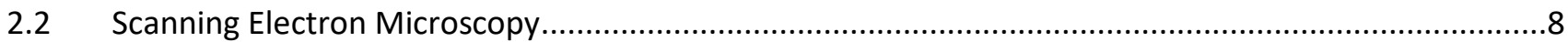

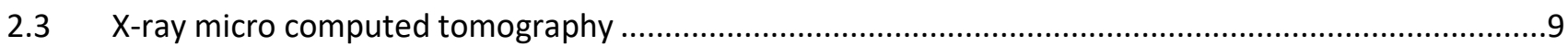

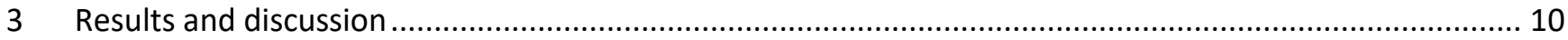

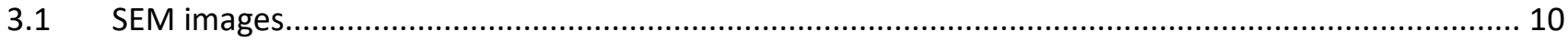

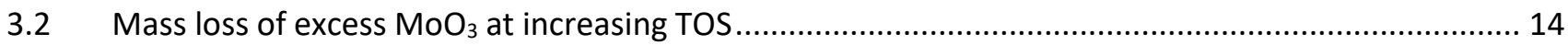

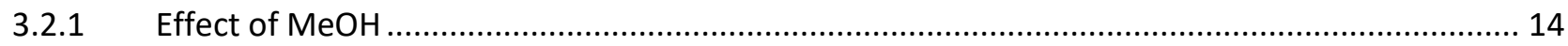

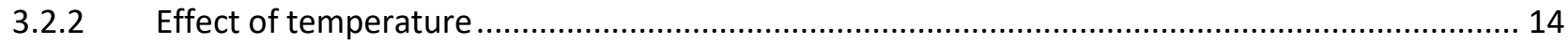

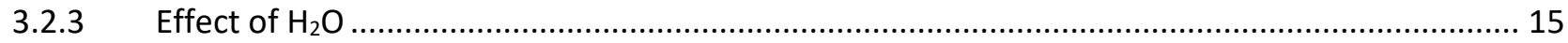

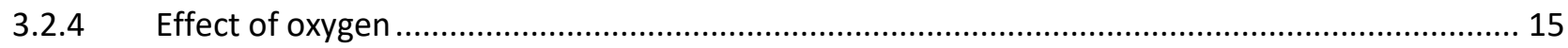

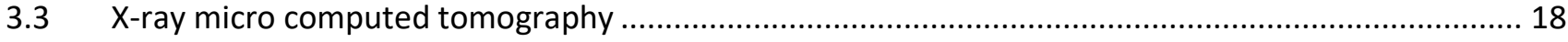

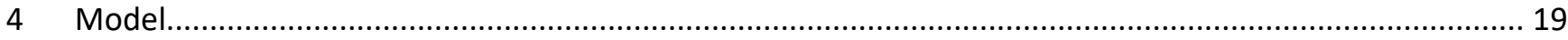

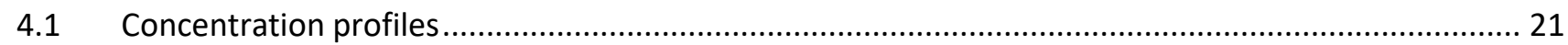

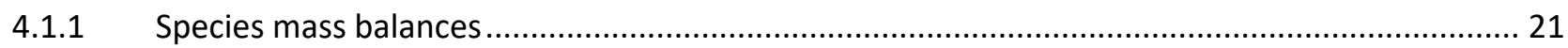

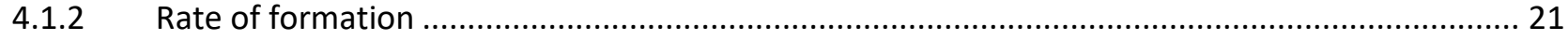

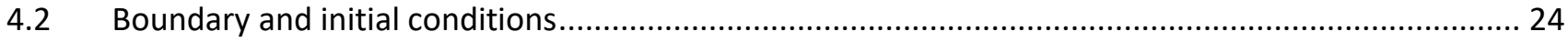

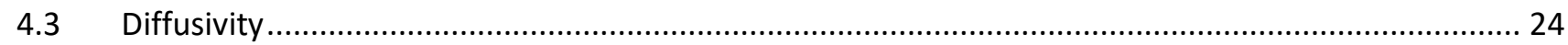

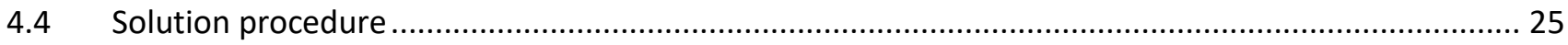

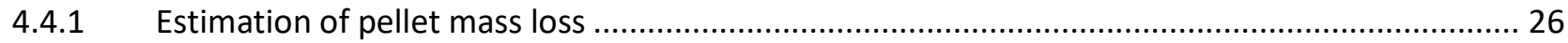

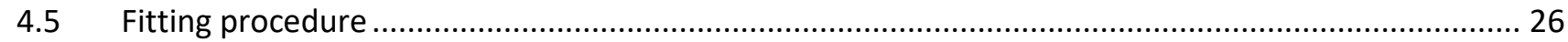

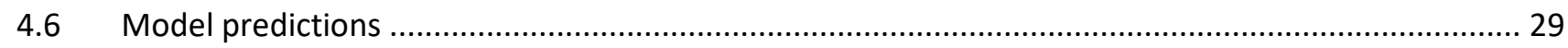

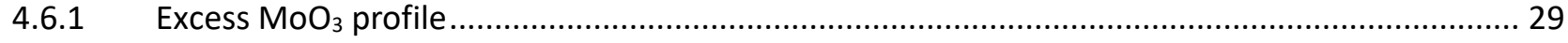

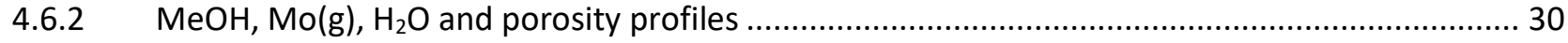

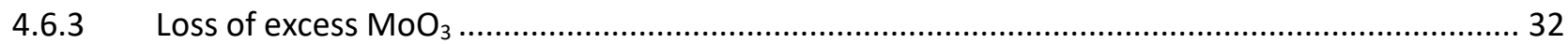

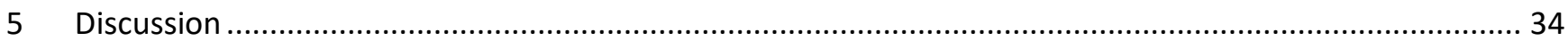




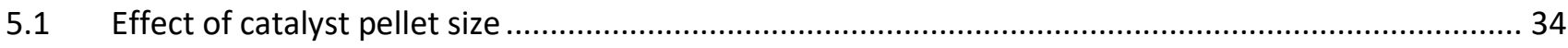

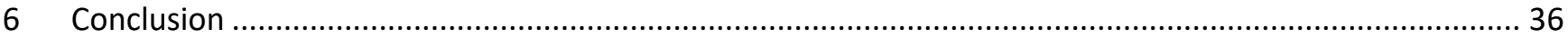

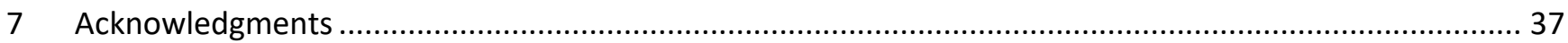

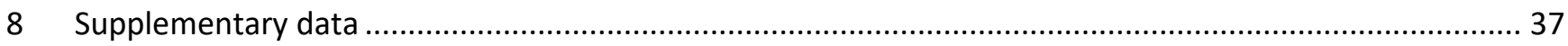

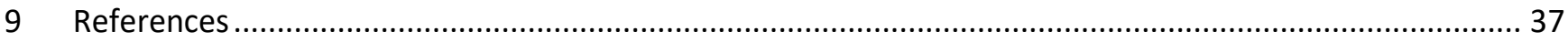

\begin{tabular}{|c|c|c|c|c|c|}
\hline \multicolumn{3}{|c|}{ Nomenclature } & $n_{A}$ & Reaction order of component A & - \\
\hline$a_{A}$ & Activity of component $A$ & - & $r_{A}$ & Reaction rate of component $A$ & {$\left[\mathrm{~mol} / \mathrm{m}^{3}\right.$ Pellet $\left./ \mathrm{s}\right]$} \\
\hline$D_{e, A}$ & $\begin{array}{l}\text { Effective diffusion coefficient } \\
\text { of component } A\end{array}$ & {$\left[\mathrm{~m}^{2} / \mathrm{s}\right]$} & $R_{h}$ & Radius of hole in pellet & [m] \\
\hline$C_{A}$ & Concentration of component $A$ & {$\left[\mathrm{~mol} / \mathrm{m}^{3}\right]$} & $R_{p}$ & Radius of pellet & [m] \\
\hline$E 0_{A}$ & $\begin{array}{l}\text { Dimensionless concentration } \\
\text { of component } A\end{array}$ & - & $t$ & time & {$[s]$} \\
\hline$C_{A}^{b}$ & $\begin{array}{l}\text { Bulk concentration of } \\
\text { component A }\end{array}$ & {$\left[\mathrm{mol} / \mathrm{m}^{3}\right]$} & $T$ & temperature & {$[\mathrm{K}]$} \\
\hline$k_{A}$ & $\begin{array}{l}\text { Rate constant of reaction A } \\
\text { and pre-exponential factor of } \\
\text { adsorption of component } A\end{array}$ & {$\left[\mathrm{~s}^{-1}\right]$} & $z$ & Dimensionless distance in pellet & - \\
\hline$K$ & Constant & - & $\rho_{A}$ & Density of component A & {$\left[\mathrm{kg} / \mathrm{m}^{3}\right]$} \\
\hline$M_{A}$ & Molar mass of component $A$ & [g/mol] & $\varepsilon$ & Porosity of pellet & - \\
\hline
\end{tabular}




\section{Introduction}

Formaldehyde $\left(\mathrm{CH}_{2} \mathrm{O}\right)$ is synthesized industrially by selective oxidation of methanol over an iron molybdate catalyst with excess molybdenum oxide according to (1)[1]:

$$
\mathrm{CH}_{3} \mathrm{OH}+1 / 2 \mathrm{O}_{2} \rightarrow \mathrm{CH}_{2} \mathrm{O}+\mathrm{H}_{2} \mathrm{O} \quad(\Delta \mathrm{H}=-156 \mathrm{~kJ} / \mathrm{mol})
$$

The reaction is carried out in a multitubular reactor (tube length $=1$ to $2 \mathrm{~m}$ ) with stoichiometric excess of oxygen $\left(\mathrm{MeOH} \approx 8-10 \%, \mathrm{H}_{2} \mathrm{O}=4-8 \%, \mathrm{O}_{2} \approx 10 \%\right.$ in $\mathrm{N}_{2}$ ) at near atmospheric pressure with complete methanol conversion in a single pass giving a formaldehyde yield around 88-92 \%, known as the Formox process [2]. The feed gas is introduced to the catalytic bed at $200-250^{\circ} \mathrm{C}$ and due to the exothermic reaction a hotspot of $350-400{ }^{\circ} \mathrm{C}$ is formed in the reactor [3].

Molybdenum forms volatile species with methanol under the reaction conditions, which can deplete the catalyst pellets of Mo and leave behind molybdenum poor zones in the catalyst bed [4], [5]. The Mo depleted zones become rich in iron oxide sites, which are less selective towards formaldehyde, forming more $\mathrm{CO}$ and potentially $\mathrm{CO}_{2}[6]-[10]$. To counter the loss of $\mathrm{Mo}$, excess $\mathrm{MoO}_{3}$ is added to the commercial catalyst, thus containing $\mathrm{Fe}_{2}\left(\mathrm{MoO}_{4}\right)_{3}$ and $\mathrm{MoO}_{3}$ as two distinct crystalline phases [7].

In the industrial reactor the volatilization of Mo occurs mainly in the initial part of the reactor, while the volatile Mo species decompose downstream in the reactor after the hotspot. The decomposed volatile Mo species deposits as needle like crystals in the void space between the catalyst pellets [3-11], which blocks the reactor and leads to increased pressure drop.

Ivanov and Dimitrov [12] performed experiments on single, industrial like reactor tubes for 15 months in the temperature range $200-340{ }^{\circ} \mathrm{C}\left(\mathrm{MeOH}=6.2 \%, \mathrm{O}_{2}=11 \%\right.$ in $\left.\mathrm{N}_{2}\right)$. Their data show that the catalyst pellets placed 
$1 / 4$ into the bed (temperature $=225-245^{\circ} \mathrm{C}$ ) were subjected to loss of Mo from the pellet surface. However, the pellet core was not affected. Furthermore, at high temperatures $\left(\mathrm{T}>300^{\circ} \mathrm{C}\right)$, they observed a reddish-brown coloration of the pellet surface due to formation of $\mathrm{FeMoO}_{4}$ and $\mathrm{Fe}_{2} \mathrm{O}_{3}$. Formation of $\mathrm{FeMoO}_{4}$ and $\mathrm{Fe}_{2} \mathrm{O}_{3}$ is also observed elsewhere $[3,13-17]$.

Anderson et al. [5] studied catalyst pellets extracted from an industrial plant after half and full lifetime and likewise observed the formation of $\mathrm{FeMoO}_{4}$ and $\mathrm{Fe}_{2} \mathrm{O}_{3}$. Furthermore, they quantified the amount of $\mathrm{Mo}$ in the catalyst pellets throughout the bed. After half and full process life time approximately the first $1 / 4$ and $1 / 3$ of the catalyst bed was depleted for Mo, respectively. Moreover, it was observed that Mo depleted pellets were subject to increased pore volume and decreased activity. The deposition of Mo downstream in the reactor predominantly occurred in the void space between the pellets after the hotspot, which is also observed elsewhere [3].

The Mo transport and downstream deposition leads to increased pressure drop over the reactor, which is one main reason for the rather short life time of only 1-2 years, after which the catalyst load must be replaced [5]. Another reason for replacement of the catalyst is loss of selectivity, which is also related to Mo depletion [14].

Popov et al. [4] studied the Mo volatilization from an iron molybdate catalyst under varying reaction conditions. They concluded that the rate of volatilization is mainly affected by the methanol concentration and suggested the formation of the volatile compounds $\mathrm{MoO}_{2}\left(\mathrm{OCH}_{3}\right)_{2}, \mathrm{MoO}_{2}(\mathrm{OH})\left(\mathrm{OCH}_{3}\right), \mathrm{MoO}_{2}\left(\mathrm{OCH}_{3}\right)$ and $\mathrm{MoO}_{2}(\mathrm{OH})$. They observed that the volatile Mo species condensed as a blue film on the reactor tube inner surface at the reactor outlet. Smith et al. [18] observed likewise a blue Mo-rich film during their experiments with single $\mathrm{MoO}_{3}$ crystals under continuous flow of a MeOH-air mixture. Using XRD they concluded that the film layer consisted of $\mathrm{Mo}_{2} \mathrm{O}_{5}\left(\mathrm{OCH}_{3}\right)_{2}$ and suggested two pathways for its formation. In the first pathway MeOH forms surface methoxy and hydroxyl groups upon adsorption on the $\mathrm{MoO}_{3}$ surface and a molybdenum oxide 
hydroxide molecule desorbs into the gas phase. The desorbed molecule then reacts with methanol in the gas phase forming $\mathrm{Mo}_{2} \mathrm{O}_{5}\left(\mathrm{OCH}_{3}\right)_{2}$. In the second pathway surface molybdenum methoxides desorb directly as the observed molybdenum oxide-methoxide. The authors suggested that the second pathway was the most plausible [18] and this was also suggested by Ivanov and Dimitrov [12] and follows:

$$
2 \mathrm{MoO}_{3}+2 \mathrm{MeOH} \rightarrow \mathrm{Mo}_{2} \mathrm{O}_{5}\left(\mathrm{OCH}_{3}\right)_{2}+\mathrm{H}_{2} \mathrm{O}
$$

The volatilization of Mo and deposition downstream in the reactor leading to pressure drop buildup is a major unsolved issue of the iron molybdate catalysts. In our laboratories the volatilization has been studied at welldefined conditions for small catalyst particles $(150-250 \mu \mathrm{m})$ [17], revealing that all excess $\mathrm{MoO}_{3}$ volatilizes rapidly $\left(\mathrm{TOS} \approx 10 \mathrm{~h}, \mathrm{MeOH}=\sim 5 \%, \mathrm{O}_{2}=10 \%\right.$ in $\mathrm{N}_{2}$ at catalyst temp $=384-398^{\circ} \mathrm{C}$ ) which is much faster than observed in industry. The results thus indicate that the rate of volatilization is strongly dependent on the catalyst particle size. In this work, the rate of volatilization of Mo from industrial catalyst pellets has been studied as a function of well-defined operating conditions and a single pellet model that take the relevant phenomena into account has, for the first time, been developed.

\section{Experimental}

\subsection{Single pellet Mo loss measurements}

The industrial iron molybdate catalyst pellets had a molar ratio of Mo to Fe of 2.4. The pellets were shaped as a cylinder with a hole in the middle $(O D=4.55 \mathrm{~mm}$, hole diameter $=1.70 \mathrm{~mm}$ and length $=4 \mathrm{~mm})$. A pellet was slid onto a thermocouple $(O D=1.5 \mathrm{~mm})$ and centered in a tubular flow reactor $(I D=6.5 \mathrm{~mm})$. A photo of the reactor and pellet can be seen in Figure S1. Three identical reactors containing one pellet each were placed in a three zone electrically heated furnace and operated in parallel. The feed gas was equally distributed between 
the reactors using rotameters and needle valves. The feed gas composition was varied in the individual experiments between 1.6-4.5 vol.\% $\mathrm{MeOH}, 2.5-10$ vol.\% $\mathrm{O}_{2}$ and 0-10.2 vol.\% $\mathrm{H}_{2} \mathrm{O}$ in $\mathrm{N}_{2}$, and was introduced at a total flowrate of $9 \mathrm{~L} / \mathrm{min}(3 \mathrm{~L} / \mathrm{min}$ per reactor, 1 bar, $273.15 \mathrm{~K}) . \mathrm{N}_{2}$ and $\mathrm{O}_{2}$ were introduced by mass flow controllers (Bronkhorst). Before entering the three reactors, a fraction of the gas was bubbled through two flasks in parallel containing $\mathrm{MeOH}$ ( $\geq 99.9 \%$, Sigma-Aldrich) and demineralized water respectively $(0.5-1.1 \mathrm{~L} / \mathrm{min}$ for $\mathrm{MeOH}$ and $0-1 \mathrm{~L} / \mathrm{min}$ for $\mathrm{H}_{2} \mathrm{O}$ ). The gas was saturated by $\mathrm{MeOH}$ and $\mathrm{H}_{2} \mathrm{O}$ respectively and the concentrations were controlled by heating the bubble-flasks $\left(45^{\circ} \mathrm{C}\right.$ for $\mathrm{MeOH}$ and $72-80{ }^{\circ} \mathrm{C}$ for $\mathrm{H}_{2} \mathrm{O}$ ). The two saturated gas flows were mixed with the remaining gas to a single feed of the desired composition before entering the reactors. The respective thermocouples were placed through the pellets hole measuring the gas temperature just before the pellet $\left(250 \pm 3,300 \pm 3\right.$ and $\left.350 \pm 3{ }^{\circ} \mathrm{C}\right)$. The mass of the pellets was measured before and after the experiments. To ensure precise measurements, the pellets were initially dried at $120^{\circ} \mathrm{C}$ and heattreated at $420^{\circ} \mathrm{C}$ after the experiments to ensure full oxidation of the catalyst [19].

\subsection{Scanning Electron Microscopy}

The Mo depleted catalyst pellets were cast in epoxy polymer and cut through the middle along the radial axis to reveal the cross sectional area of the pellet. The samples were coated with an electron conductive layer of carbon prior to investigation. Scanning Electron Microscopy (SEM) images were acquired in an Environmental SEM, FEI XL30 FEG, at $15 \mathrm{kV}$ using the backscattered electron signal. EDS analyses were acquired in the electron microscope without standards at $15 \mathrm{kV}$ with an EDAX liquid Nitrogen cooled Si(Li) detector and a liquid Nitrogen free Thermo Silicon Drift Detector (SDD). 


\subsection{X-ray micro computed tomography}

X-ray tomograms were obtained using a ZEISS XRadia 410 Versa instrument. The instrument was operated at $140 \mathrm{kV}$ and $10 \mathrm{~W}$ using the high energy 2 (HE2) filter and a $4 \mathrm{X}$ objective. For measurements of the whole sample 1601 projections with $5 \mathrm{sec}$ exposure time were used, which resulted in a total measurement time of 3:02 h:min. A pixel size of $4.6 \mu \mathrm{m}$ was obtained using a $2 \times 2$ binning. Image reconstruction was performed using the built-in acquisition and reconstruction software package provided by ZEISS.

Visualization, image analysis and phase segmentation were performed using the commercial software Avizo 9.5.0 (FEI). The following procedure was used: Initially the reconstructed volume of the whole catalyst was filtered using a nonlocal means filter which was applied on the individual xy planes with a search window of 21 pixels, a local neighborhood of 5 pixels, a similarity value 0.6 and using an adaptive choice of lambda. The pellet was segmented using the magic wand tool and characterizing the different phases by the following grey scale intensity values (outer air $=0-13658$, depleted phase $=13659-27152$ and non-depleted phase $=27153-65535$ ) . Both phases contained some holes which were not included in the segmentation. In order to fill these nonassigned holes in the volume, the interactive watershed tool provided by the segmentation editor was used. It uses a gradient magnitude image calculated by a quick Canny method, which controls the expansion of the markers used for the watershed expansion. After this step the depleted and non-depleted phases were segmented and the materials statistics module was applied to obtain the volumetric information of the two phases. 


\section{Results and discussion}

\subsection{SEM images}

The scanning electron microscopy (SEM) images of the pellets cross section coupled with energy-dispersive Xray spectroscopy (EDS) showed the depletion of Mo with increasing time on stream. In Figure 1 some characteristic samples are shown and more samples are shown in the supporting information (Figures S2 -S7).

For the fresh pellet (Figure 1 (a)) a mainly light grey $(\mathrm{Mo} / \mathrm{Fe}=2.4$ atomic ratio) appearance throughout the pellet was observed with some smaller Mo rich inclusions (white) and voids (black)(Figure S2). For an exposed pellet (Figure 1 (b)) (Conditions: $4.4 \% \mathrm{MeOH}, 0 \% \mathrm{H}_{2} \mathrm{O}, 10 \% \mathrm{O}_{2}$ in $\mathrm{N}_{2}, 350^{\circ} \mathrm{C}$ and time on stream (TOS) $=70 \mathrm{~h}$ ) a Mo depleted, dark grey layer at the pellet surface was observed. EDS area scans at the surface region (Figure 2) revealed that the depleted layer had an atomic ratio of approximately $\mathrm{Mo} / \mathrm{Fe}=1.5$, corresponding to pure $\mathrm{Fe}_{2}\left(\mathrm{MoO}_{4}\right)_{3}$. In the interior of the pellet the composition was unchanged with a Mo/Fe ratio of 2.4. For pellets exposed to $350^{\circ} \mathrm{C}$ a zone with increased $\mathrm{Mo}(\mathrm{Mo} / \mathrm{Fe}=2.8)$ compared to the fresh pellet was observed behind the depleted layer towards the center (Figure 2 (c)). For the pellets exposed to $350^{\circ} \mathrm{C}$ and TOS $\geq 160 \mathrm{~h}$ (Figure 3), the composition in the depleted layer was approximately $\mathrm{Mo} / \mathrm{Fe}=1$, which indicates that the initial $\mathrm{Fe}_{2}\left(\mathrm{MoO}_{4}\right)_{3}$ was reduced to the less $\mathrm{Mo}$ rich $\mathrm{FeMoO}_{4}$ phase. Reduction of $\mathrm{Fe}_{2}\left(\mathrm{MoO}_{4}\right)_{3}$ and formation of FeMoO 4 is also observed elsewhere in the literature $[17,20]$.

Water in the feed gas (10\%) slowed down the development of the depletion layer, and Mo deposition inside the pellet was not observed at $\sim 350{ }^{\circ} \mathrm{C}$ (Figure 4).

For the depleted pellet treated with low oxygen concentration (Figure 5)(Conditions: $3.5 \% \mathrm{MeOH}, 0 \% \mathrm{H}_{2} \mathrm{O}, 2.5$ $\% \mathrm{O}_{2}$ in $\mathrm{N}_{2}, 300^{\circ} \mathrm{C}$ and TOS $=288 \mathrm{~h}$ ) white inclusions at the pellet surface region were observed, and shown by EDS to be Mo rich particles (Figure S7). The Mo inclusions were present both in the depletion layer and further 
into the pellet. No inclusions were present in the first $\sim 100 \mu \mathrm{m}$ from the pellet surface. Volatilization of Mo has been observed to increase at lower oxygen concentration in the literature [4]. However, in this study the oxygen concentration in the feed gas was shown to have no effect on the overall mass loss of the pellet (Figure S12). To the authors knowledge the formation of Mo inclusions at low oxygen concentration $\left(2.5 \% \mathrm{O}_{2}\right)$ has not been observed elsewhere in the literature, and is not fully understood.
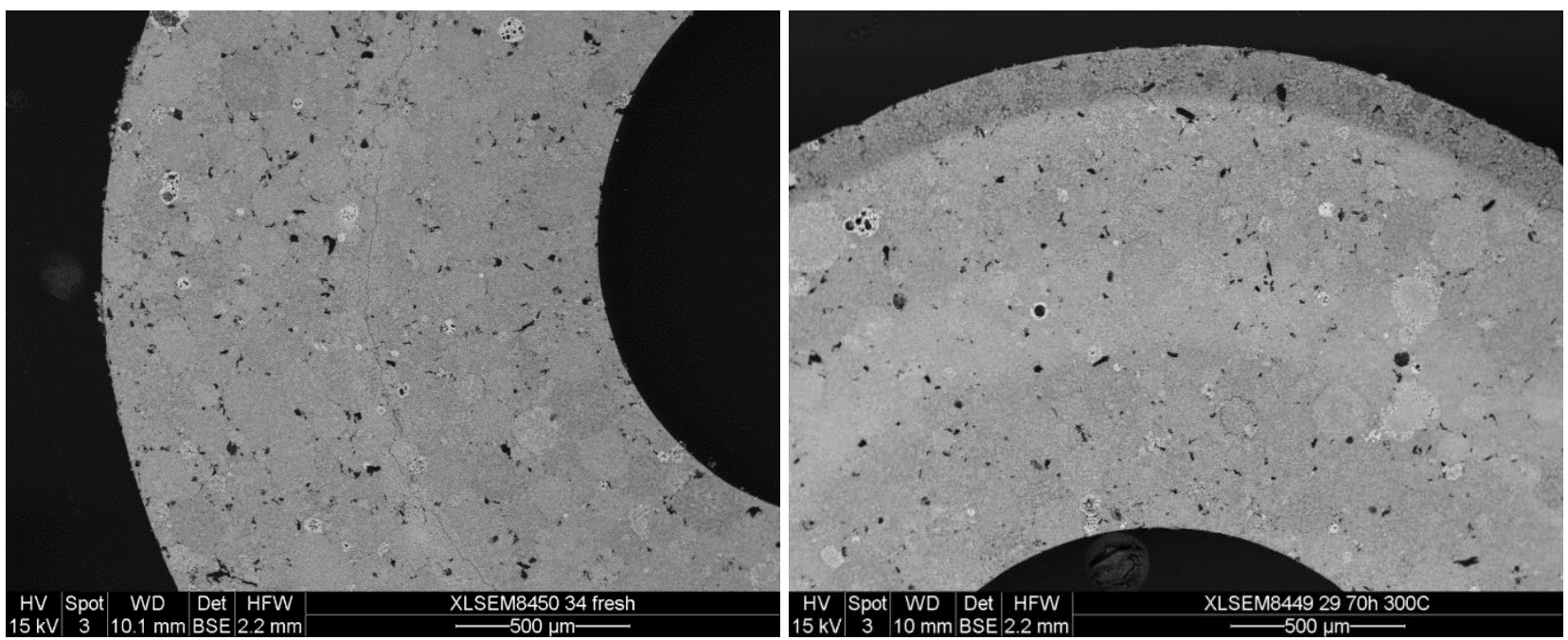

Figure 1 - SEM images of the cross section of fresh (a) and depleted (b) pellets (Conditions: $4.5 \% \mathrm{MeOH}, 0 \% \mathrm{H}_{2} \mathrm{O}, 10 \% \mathrm{O}_{2}$ in $\mathrm{N}_{2}, 300$ ${ }^{\circ} \mathrm{C}$ and TOS $=71 \mathrm{~h}$ ). Light grey indicates Mo rich areas, dark grey indicates Mo depleted areas and white indicate Mo rich inclusions.
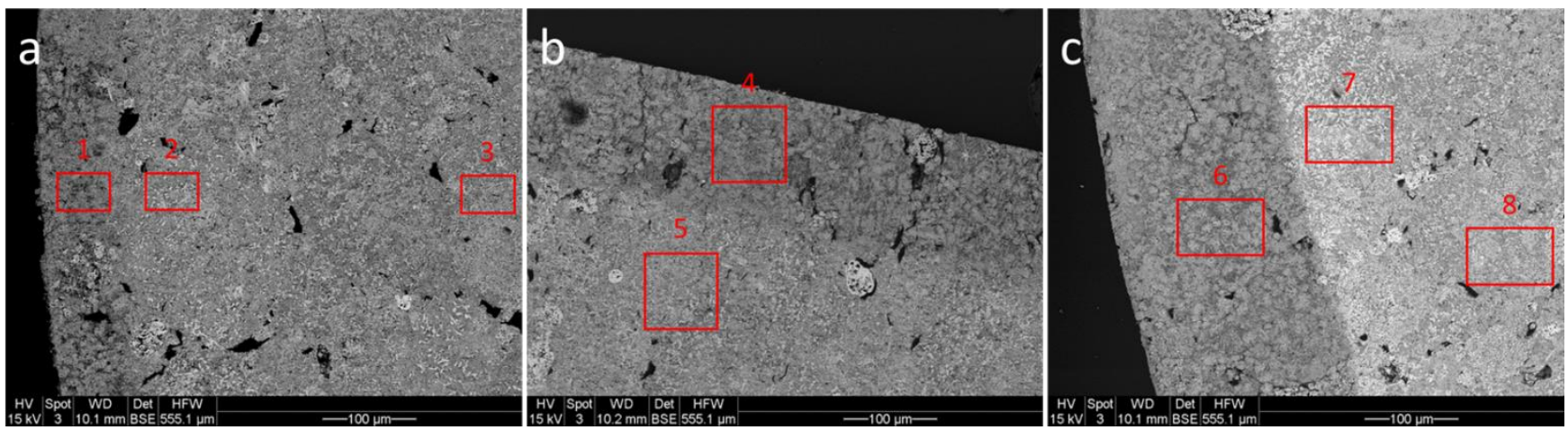

Figure 2 - SEM images of the cross sectional surface regions of depleted pellets treated at (a) $250{ }^{\circ} \mathrm{C}$, (b) $300{ }^{\circ} \mathrm{C}$ and (c) $350{ }^{\circ} \mathrm{C}$. TOS $=$ 71-78 h, 4.4-4.5 \% MeOH, $0 \% \mathrm{H}_{2} \mathrm{O}, 10 \% \mathrm{O}_{2}$ in $\mathrm{N}_{2}$. Mo/Fe: area $1=1.6$, area $2=2.5$, area $3=2.4$, area $4=1.5$, area $5=2.4$, area $6=1.6$, area $7=2.8$ and area $8=2.5$. 


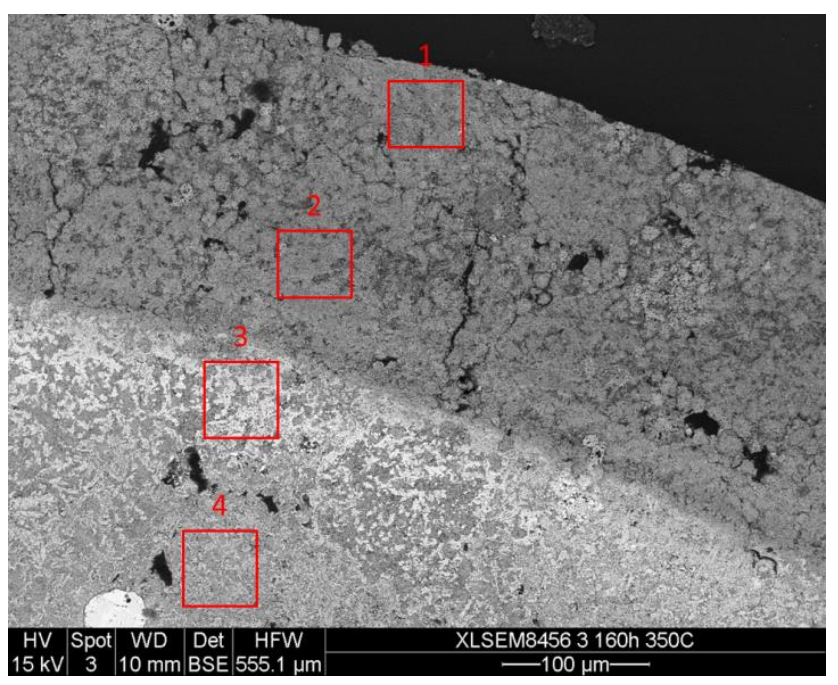

Figure 3 - SEM image of the cross sectional surface region of a depleted pellet treated at $350{ }^{\circ} \mathrm{C}$ for $160 \mathrm{~h}$ (Conditions: $4.4 \% \mathrm{MeOH}, 0$ $\% \mathrm{H}_{2} \mathrm{O}, 10 \% \mathrm{O}_{2}$ in $\mathrm{N}_{2}$ ). Mo/Fe: area $1=1.1$, area $2=1.2$, area $3=3.0$ and area $4=2.5$.

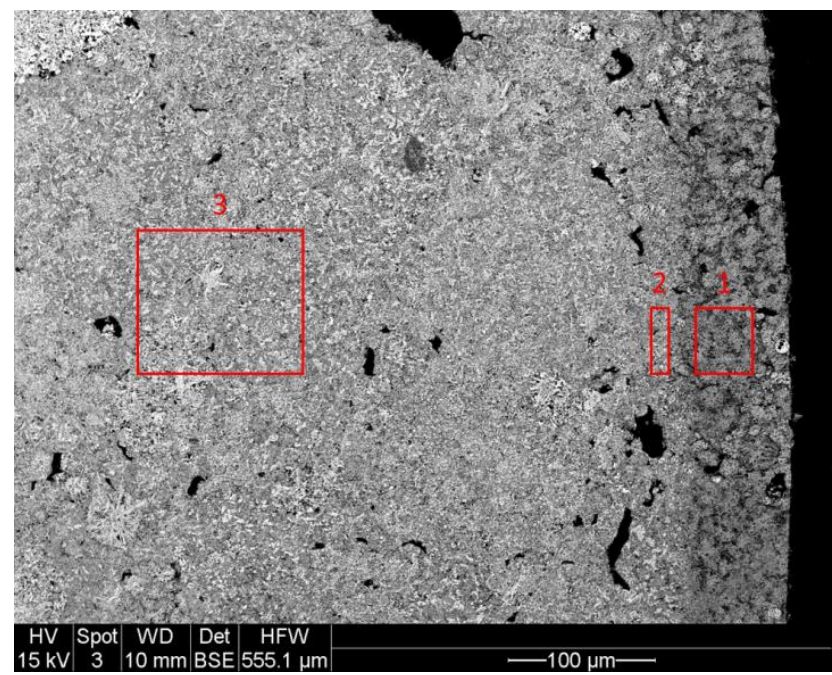

Figure 4 - SEM image of the cross sectional surface region in a depleted pellet treated at $350{ }^{\circ} \mathrm{C}$ for $73 \mathrm{~h}$ with water added to the gas phase (Conditions: $4.2 \% \mathrm{MeOH}, 9.3 \% \mathrm{H}_{2} \mathrm{O}, 10 \% \mathrm{O}_{2}$ in $\mathrm{N}_{2}$ ). $\mathrm{Mo} / \mathrm{Fe}$ : area $1=1.7$, area $2=2.2$ and area $3=2.5$. 


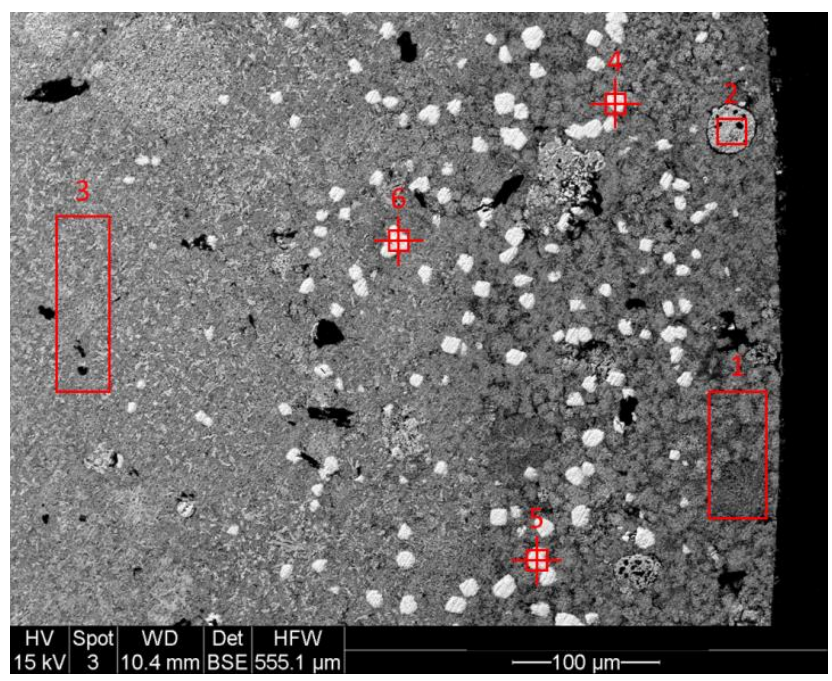

Figure 5 - SEM image of the cross sectional surface region in a depleted pellet treated at $300^{\circ} \mathrm{C}$ for $288 \mathrm{~h}$ with low oxygen concentration (Conditions: $3.50 \% \mathrm{MeOH}, 0 \% \mathrm{H}_{2} \mathrm{O}, 2.5 \% \mathrm{O}_{2}$ in $\mathrm{N}_{2}$ ). $\mathrm{Mo} / \mathrm{Fe}$ : area $1=1.7$, area $2=1.6$, area $3=2.5$, area $4=12.6$, area $5=8.0$ and area $6=5.1$.

It is widely observed in the literature that Mo in the iron molybdate catalyst can form volatile species with $\mathrm{MeOH}$ and be transported away from the catalyst $[2,3,7]$, which was also observed in the current work as blue molybdenum deposits at the reactor outlet. The SEM images combined with EDS of the depleted pellets show that the excess $\mathrm{MoO}_{3}$ present in the catalyst forms volatile Mo species which diffuse through the pellet. At the pellet surface the Mo species leave the pellet and enter the bulk gas phase and is carried out of the reactor. The depletion layer has a rather sharp front, which indicates that the volatilization reaction is equilibrium limited and that the equilibrium is established at the front. The volatile Mo species formed at the front will also diffuse into the pellet. At $\sim 350^{\circ} \mathrm{C}$ deposition of excess Mo inside the pellet is observed. As the temperature increases the $\mathrm{MeOH}$ concentration through the pellet is decreasing faster due to the higher rate of reaction. The volatile Mo species likely decomposes inside the pellet pores as the $\mathrm{MeOH}$ concentration decreases towards the pellet center due to the equilibrium between $\mathrm{MeOH}$ and the $\mathrm{Mo}$ species according to reaction (2). The formation of $\mathrm{FeMoO}_{4}$ is only observed at $350{ }^{\circ} \mathrm{C}$, which indicates that $\mathrm{Fe}_{2}\left(\mathrm{MoO}_{4}\right)_{3}$ is significantly more stable than $\mathrm{MoO}_{3}$ and that volatilization of $\mathrm{Mo}$ only occurs from the $\mathrm{MoO}_{3}$ phase at moderate temperatures $\left(\leq 300^{\circ} \mathrm{C}\right)$ under the applied reaction conditions. 


\subsection{Mass loss of excess $\mathrm{MoO}_{3}$ at increasing TOS}

As the pellets underwent Mo depletion they were likewise subject to a corresponding mass loss with increasing time on stream. Figure 6-Figure 8 show the mass loss of the catalyst pellets at increasing TOS at varying temperature, $\mathrm{MeOH}$ and water concentrations. The mass loss is converted to the corresponding loss of the excess $\mathrm{MoO}_{3}$ phase assuming that only this phase forms volatile Mo species. The $95 \%$ confidence interval of the mass loss measurement were calculated to $\pm 6.9 \%$ (ESI section 3 ).

All applied reaction conditions showed the same trend in the mass loss rate with increasing TOS. Initially the mass loss was fast, due to the high $\mathrm{MeOH}$ concentration at the pellet surface, which quickly volatilizes the excess $\mathrm{MoO}_{3}$ present there, according to (2). After 10-20 h on stream the rate decreases, due to the effect of decreased $\mathrm{MeOH}$ concentration at the developed depletion layer front and diffusion limitations of the formed Mo species out of the pellet. These inhibiting effects increasingly slowed down the rate of depletion with time on stream.

\subsubsection{Effect of $\mathrm{MeOH}$}

The $\mathrm{MeOH}$ concentration strongly affects the mass loss rate of the catalyst pellet (Figure 6). As discussed in the introduction similar results have been observed for Mo volatilization in the literature $[4,18]$.

\subsubsection{Effect of temperature}

The volatilization rate of solid $\mathrm{MoO}_{3}$ in the catalyst with $\mathrm{MeOH}(2)$ increases with increasing temperature (Figure 7). However, the rate of reaction for $\mathrm{MeOH}$ to formaldehyde will likewise increase, which counteract the rate of volatilization due to the decreasing $\mathrm{MeOH}$ concentration inside the pellet. Furthermore, the rate of diffusion of the gaseous species out of the pellet will also increase at increasing temperature. The overall loss of Mo from the pellet is affected by all these contributions and the net effect is an increased rate of Mo loss 
from the pellets with increasing temperature at the applied reaction conditions ( $\mathrm{MeOH}=\sim 4.4 \%, \mathrm{H}_{2} \mathrm{O}=0 \%, \mathrm{O}_{2}$ $=10 \%$ in $\mathrm{N}_{2}$ ).

\subsubsection{Effect of $\mathrm{H}_{2} \mathrm{O}$}

An increased $\mathrm{H}_{2} \mathrm{O}$ concentration decreases the mass loss rate, which indicates that $\mathrm{H}_{2} \mathrm{O}$ inhibits the volatilization reaction (2)(Figure 8). $\mathrm{H}_{2} \mathrm{O}$ is likewise known to inhibit the oxidation of $\mathrm{MeOH}(1)$ [21], which will increase the $\mathrm{MeOH}$ concentration through the pellet and an increased volatilization rate might be expected. However, the mass loss measurements show this is not the case and that $\mathrm{H}_{2} \mathrm{O}$ overall inhibits the mass loss of the pellet. This indicates that the volatile Mo species are formed during the catalytic cycle, likely as a low concentration side product.

\subsubsection{Effect of oxygen}

Varying the oxygen concentration $\left(2.5-10 \% \mathrm{O}_{2}, \sim 2 \% \mathrm{MeOH}, 0 \% \mathrm{H}_{2} \mathrm{O}\right.$ in $\mathrm{N}_{2}$ ) had no effect on the mass loss rate of the catalyst pellet (Figure S3). Mo-rich inclusions are observed with SEM at an $\mathrm{O}_{2}$ concentration of $2.5 \%$ (Figure 5), indicating that Mo is mobilized but retained in the catalyst pellet as Mo-rich inclusions. 


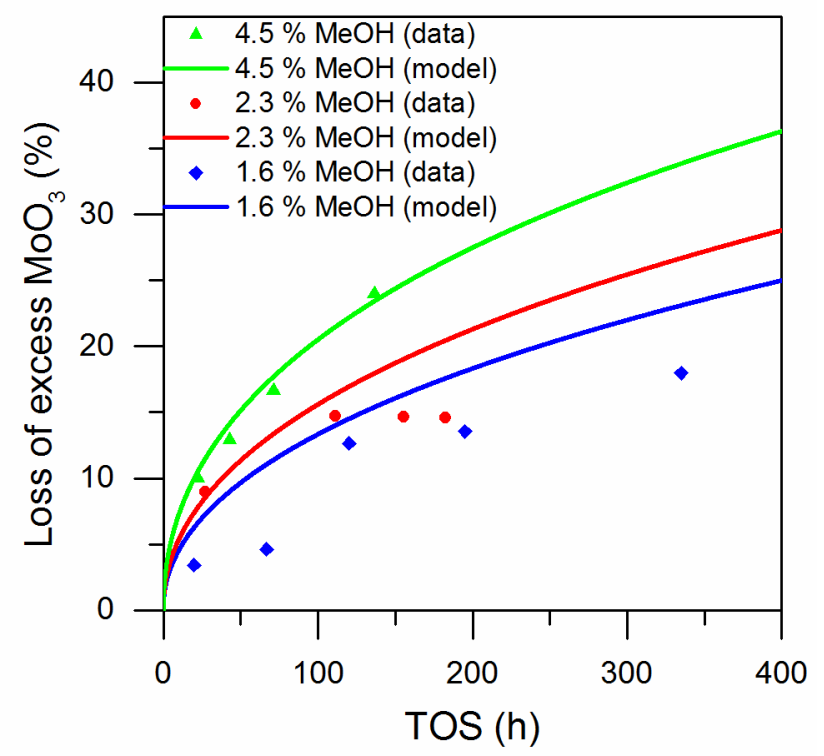

Figure 6 - Influence of $\mathrm{MeOH}$ concentration on the overall loss of excess $\mathrm{MoO}_{3}$ in the pellets as a function of TOS. Treated at MeOH = 1.6-4.5 \%, $\mathrm{H}_{2} \mathrm{O}=0 \%, \mathrm{O}_{2}=10 \%$ in $\mathrm{N}_{2}$ at $300{ }^{\circ} \mathrm{C}$. $\mathrm{Mo} / \mathrm{Fe}=2.4$. Flow rate $=3000 \mathrm{~mL} / \mathrm{min}(1 \mathrm{bar}, 273.15 \mathrm{~K})$.

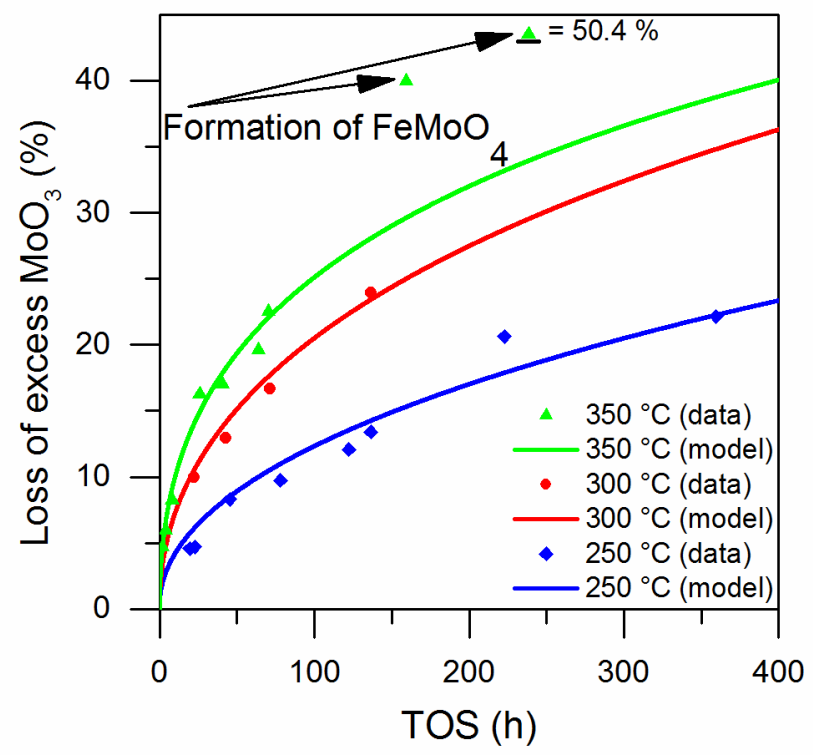

Figure 7 - Influence of temperature on the overall loss of excess $\mathrm{MoO}_{3}$ in the pellets as function of TOS. Treated at $\mathrm{MeOH}=4.4-4.5 \%$, $\mathrm{H}_{2} \mathrm{O}=0 \%, \mathrm{O}_{2}=10 \%$ in $\mathrm{N}_{2}$ at $250-350^{\circ} \mathrm{C}$. Mo/Fe $=2.4$. Flow rate $=3000 \mathrm{~mL} / \mathrm{min}(1 \mathrm{bar}, 273.15 \mathrm{~K})$. Data point at $350{ }^{\circ} \mathrm{C}$ and $\mathrm{TOS}=238 \mathrm{~h}$ is equal to $50.4 \%$ loss of excess $\mathrm{MoO}_{3}$. 


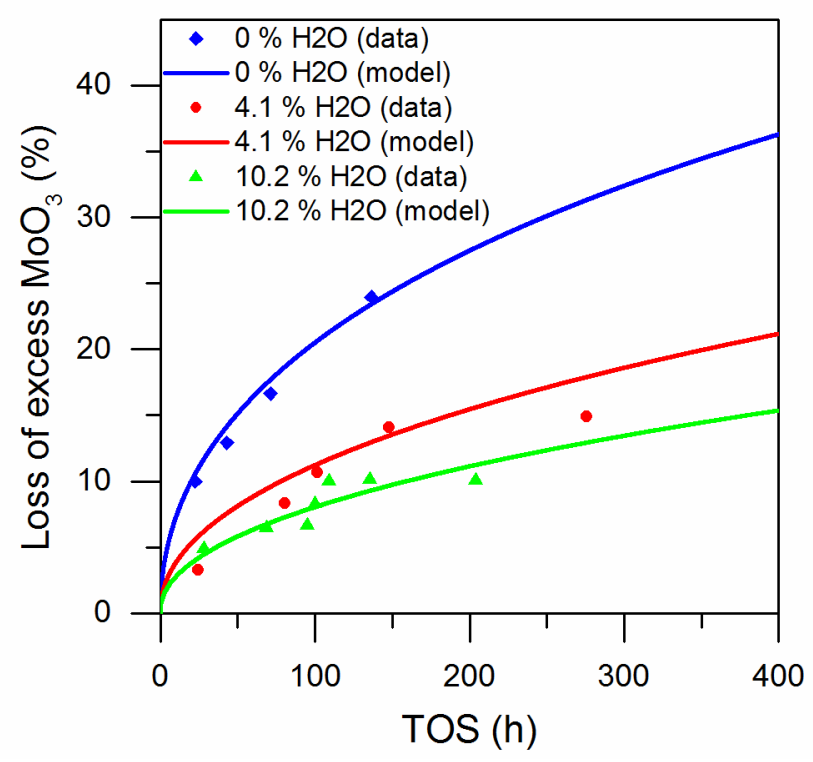

Figure 8 - Influence of water concentration on the overall loss of excess $\mathrm{MoO}_{3}$ in the pellets as function of TOS. Treated at MeOH = 4.0-4.5 \%, $\mathrm{H}_{2} \mathrm{O}=0-10.2 \%, \mathrm{O}_{2}=10 \%$ in $\mathrm{N}_{2}$ at $300{ }^{\circ} \mathrm{C}$. $\mathrm{Mo} / \mathrm{Fe}=2.4$. Flow rate $=3000 \mathrm{~mL} / \mathrm{min}(1 \mathrm{bar}, 273.15 \mathrm{~K})$. 


\subsection{X-ray micro computed tomography}

For non-destructive information on a whole catalyst pellet and complementary insights to SEM cross section images, X-ray micro computed tomography $(\mu-\mathrm{CT})$ was conducted on a depleted pellet (Figure 9) after $64 \mathrm{~h}$ on stream at $350{ }^{\circ} \mathrm{C}, \mathrm{MeOH}=4.4 \%, \mathrm{H}_{2} \mathrm{O}=0 \% \mathrm{O}_{2}=10 \%$ in $\mathrm{N}_{2}$. This technique revealed the $\mathrm{MoO}_{3}$ depletion development throughout the entire pellet. Figure 9 shows an image of the entire axial cross section of the depleted pellet. The depletion layer has evolved evenly from the outer surface of the pellet and from the top surface facing towards the reactor inlet. Only a slight depletion has evolved from the inner surface and from the bottom surface facing away from the reactor inlet. During exposure the inner hole of the pellet was blocked by a thermocouple and the downstream end of the pellet was facing a spacer centering the pellet in the reactor (see Figure S1). The blocking of the inner and end surface lead to only slight depletion from these surfaces. Segmentation of the depleted and non-depleted areas of the pellet showed that 20.3 vol.\% (10.8 of $53.1 \mathrm{~mm}^{3}$ ) of the entire pellet were subject to depletion, corresponding to a mass loss of $6.19 \%$ at $\mathrm{Mo} / \mathrm{Fe}=$

2.4. The measured mass loss is however slightly lower (5.97\%), since some of the volatilized $\mathrm{MoO}_{3}$ have moved inside the pellet. The depletion layer thickness in the radial direction was measured to approximately $110 \mu \mathrm{m}$.

Images of the cross-section in the radial plane through the pellet (Figure S8) and a movie showing the depletion through the entire pellet can be seen in the ESI. 


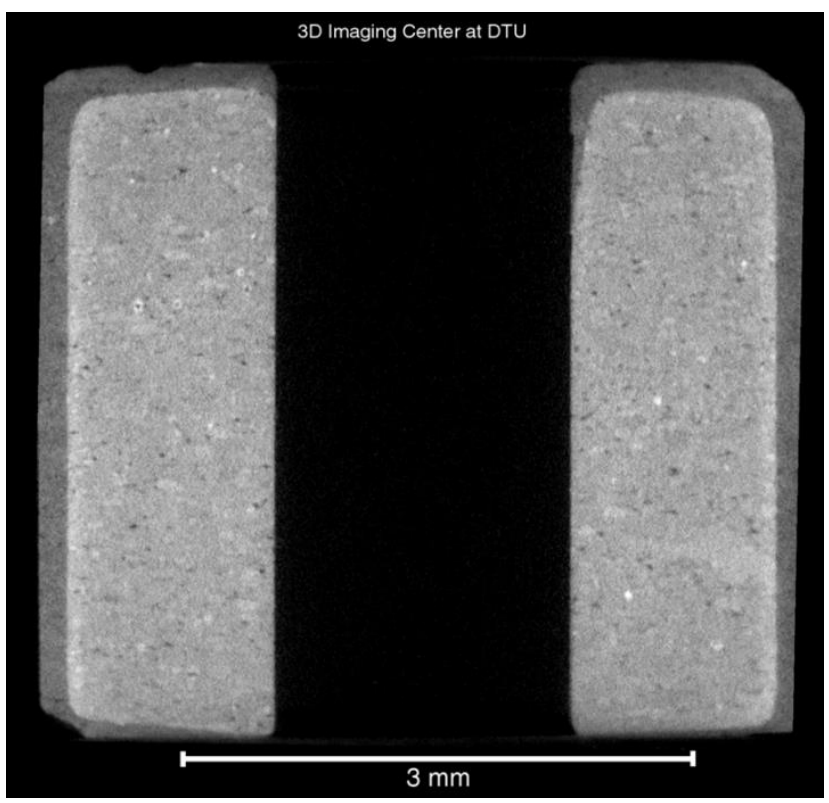

Figure 9 - X-ray micro computed tomography image of the entire axial cross section in a depleted pellet (Conditions: $4.4 \% \mathrm{MeOH}, 0$ $\% \mathrm{H}_{2} \mathrm{O}, 10 \% \mathrm{O}_{2}$ in $\mathrm{N}_{2}, 350{ }^{\circ} \mathrm{C}$ and TOS $=64 \mathrm{~h}$ ). Dark grey indicates the less X-ray absorbing depleted layer and light grey indicates a higher absorbing non-depleted material, while white indicates areas of strong absorption due to Mo deposition.

\section{Model}

In this section, the single catalyst pellet model is derived describing the concentration profiles of $\mathrm{MeOH}, \mathrm{H}_{2} \mathrm{O}$, solid $\mathrm{MoO}_{3}$ and volatile Mo-species. Methanol diffuses from the bulk gas phase into the pellet at the surface, where it is primarily oxidized to formaldehyde and water, which diffuses out of the pellet. Furthermore, methanol and solid $\mathrm{MoO}_{3}$ in the catalyst react to form the volatile Mo-species. The volatile Mo-species can either diffuse inwards or outwards the pellet or it can decompose and depositing solid $\mathrm{MoO}_{3}$. The volatile Mospecies enters the bulk gas phase at the pellet surface. There is no diffusion of solid $\mathrm{MoO}_{3}$, however it is removed during volatilization. 
The industrial catalyst pellets are cylindrical with a hole in the middle. During experiments the pellets were placed on a thermocouple blocking the hole. Only small amounts of Mo volatilization were observed from the inner surface and the end surface facing away from the reactor inlet (Figure 9). Figure 10 shows a schematic of the cylindrical cross section.

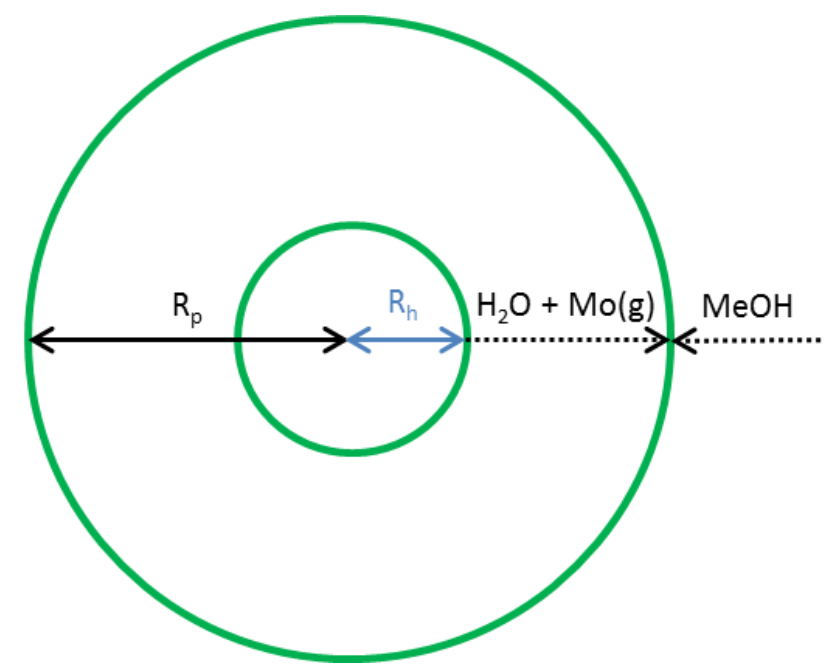

Figure 10 - Schematic of the catalyst pellet system with the cross sectional view of the cylindrical shape of the. The green lines are the pellet surface. The radius of the pellet is $R_{p}$ and the radius of the hole in the pellet is $R_{h}$.

The following assumptions have been made during the derivation and solution of the single catalyst pellet model:

- The volatilization reaction of $\mathrm{MoO}_{3}$ with $\mathrm{MeOH}$ follows the reversible reaction:

$$
\mathrm{MoO}_{3}(\mathrm{~s})+\mathrm{CH}_{3} \mathrm{OH}(\mathrm{g}) \square \quad \mathrm{Mo}(\mathrm{g})
$$

- The volatile $\mathrm{Mo}$ species is $\mathrm{Mo}_{2} \mathrm{O}_{5}\left(\mathrm{OCH}_{3}\right)_{2}$

- Mo in iron molybdate is not volatile.

- No film resistance at the pellet surface. 


\subsection{Concentration profiles}

\subsubsection{Species mass balances}

The concentration profiles in the pellet can be calculated by setting up a shell mole balance over a small section of the pellet, taking the diffusion in and out of the element into account, and the respective formation and accumulation at the position $\left(\mathrm{S} 1^{\dagger}\right)$. The diffusion can be calculated by Fick's first law of diffusion ( $\mathrm{S} 2+$ where the diffusion coefficient in the pellet is dependent on the porosity (S3+). Due to the volatilization of Mo in the pellet the porosity is dependent on the time due to the changing concentration of solid Mo (S4-S5+) at a given position. The balance is reduced (S6-S7+) and becomes Equation (3) (Table 1), where $r$ equal to zero is at the

center of the cylindrical pellet, $R_{h}$ is at the inner pellet surface and $R_{p}$ is at the outer surface. With respect to solid Mo there is no diffusion and the diffusion coefficient is thus equal to zero.

\subsubsection{Rate of formation}

\subsubsection{1 $\mathrm{MeOH}$ and $\mathrm{H}_{2} \mathrm{O}$}

Bibin and Popov [22] studied the kinetics of selective oxidation of $\mathrm{MeOH}$ over iron molybdate catalysts (1) and suggested a rate expression (4), which takes the inhibition by water and $\mathrm{MeOH}$ into account. Water is formed during oxidation of $\mathrm{MeOH}$ to formaldehyde (5). The selective oxidation reaction is much faster than the volatilization of solid $\mathrm{Mo}$ in the catalyst. Only the contribution from the oxidation of $\mathrm{MeOH}$ is taken into account with respect to the rate of reaction of $\mathrm{MeOH}$ and $\mathrm{H}_{2} \mathrm{O}$. 


\subsubsection{Solid and volatile Mo}

$\mathrm{MeOH}$ and solid $\mathrm{MoO}_{3}$ in the catalyst reversibly form a volatile gaseous Mo species. The obtained mass loss data at varying conditions and TOS, reveal that water inhibits the volatilization reaction of Mo. The reaction mechanism is not fully understood and several volatile Mo species have been proposed as discussed above, of which $\mathrm{Mo}_{2} \mathrm{O}_{5}\left(\mathrm{OCH}_{3}\right)_{2}$ appears to be the most likely species [4][18]. The rate expression with respect to volatilization of Mo can be described in several ways. Two rate expressions have been tested in the model and fitted to the experimental data. The first expression was a power-law rate expression, with different orders in both the forward reaction between $\mathrm{MeOH}$ and solid $\mathrm{MoO}_{3}$ and backward reaction between $\mathrm{Mo}_{2} \mathrm{O}_{5}\left(\mathrm{OCH}_{3}\right)_{2}$ and $\mathrm{H}_{2} \mathrm{O}$ (2). This expression was found to overestimate the deposition of $\mathrm{Mo}$ inside the pellet at zero $\mathrm{H}_{2} \mathrm{O}$ bulk concentration. Both the reaction rates are fast and an equilibrium is approximately reached at the depletion front. However, for zero $\mathrm{H}_{2} \mathrm{O}$ at the pellet surface, only the forward reaction will take place, leading to almost instantaneous volatilization of Mo at the pellet surface. According to that model the formed volatile Mospecies will then mistakenly diffuse inside the pellet and decompose where water is present due to the oxidation of $\mathrm{MeOH}$. To better implement the inhibiting effect of water a Langmuir-Hinshelwood type expression is used for the forward reaction and only the concentration of the volatile Mo-species is taken into account for the backward rate. Due to the limited amount of data, a temperature dependency of the water inhibition is not included. The reversible volatilization rate expression with respect to gaseous Mo, Equation (6), and solid Mo, Equation (7), is shown in Table 1. $a_{\mathrm{MoO}_{3}}$ has the value of one when there is solid $\mathrm{MoO}_{3}$ present and zero when there is not. 
Table 1 - Equations for calculation of the concentration profiles in the pellet with respect to $\mathrm{MeOH}, \mathrm{H}_{2} \mathrm{O}$, volatile $\mathrm{Mo}$ species and solid $\mathrm{MoO}_{3}$. With respect to $\mathrm{MoO}_{3}$ the diffusion $\left(D_{e, \mathrm{MoO}_{3}}^{0}\right)$ is zero.

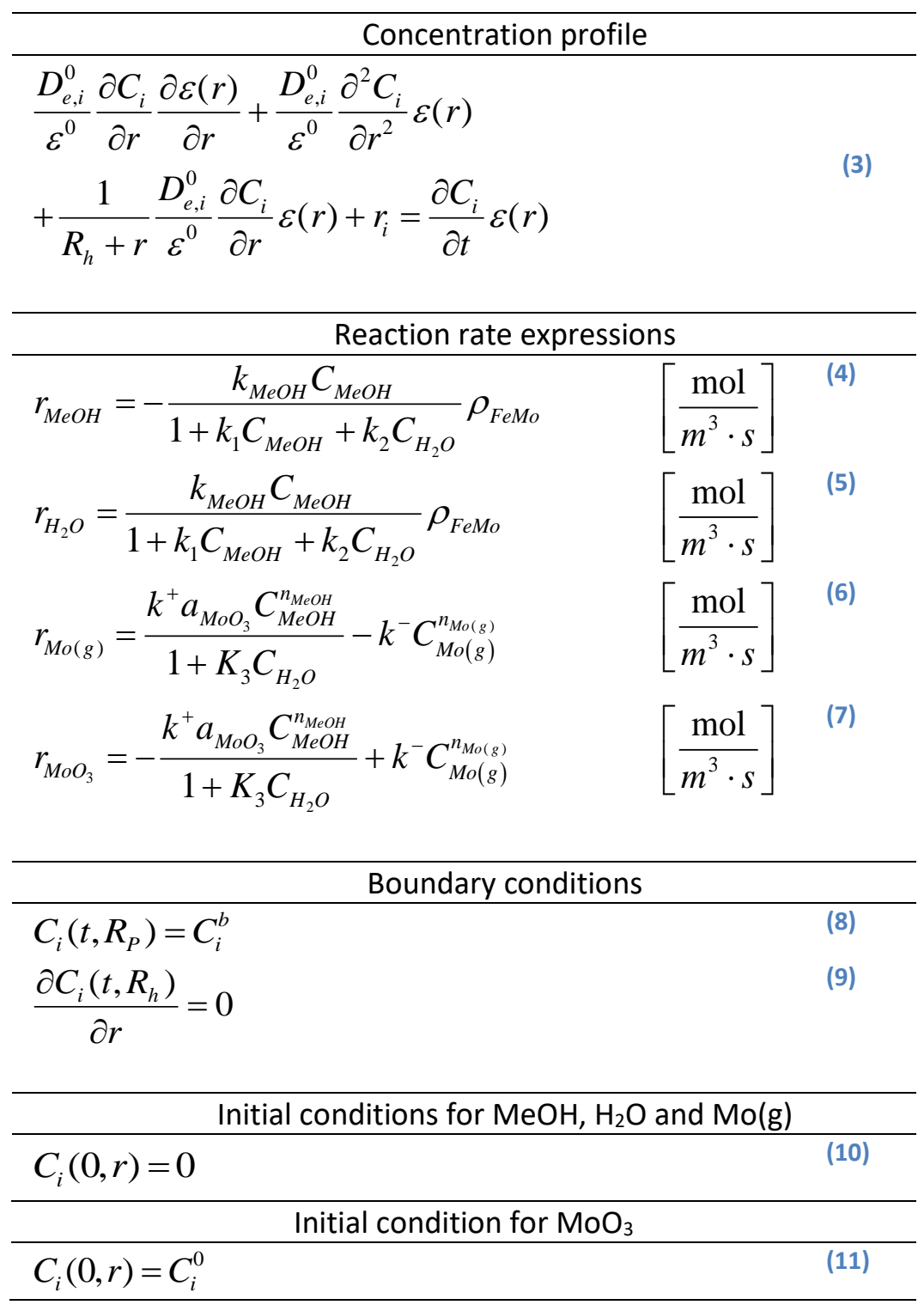




\subsection{Boundary and initial conditions}

It is assumed that there is no gas film layer at the catalyst surface and thus the $\mathrm{MeOH}$ and $\mathrm{H}_{2} \mathrm{O}$ concentrations are equal to the bulk concentrations. Furthermore, it is assumed that there is no gradient at the inner catalyst surface since it is blocked by the thermocouple on which the pellet is hanging. It is assumed that there is no initial concentration of gaseous species in the pellet. The boundary and initial conditions become Equations (8)(11) in (Table 1).

\subsection{Diffusivity}

The effective diffusion coefficient of $\mathrm{MeOH}, D_{e, M e O H}^{0}\left(\mathrm{~m}^{2} / \mathrm{s}\right)$, at a given temperature, $T$ is estimated by:

$$
D_{e, \mathrm{MeOH}}^{0}=K_{1}\left(\frac{T^{K_{2}}}{T_{\mathrm{Ref}}^{K_{2}}}\right)
$$

Where $K_{1}$ and $K_{2}$ are constants and $T_{\text {Ref }}$ is a reference temperature.

The effective diffusion coefficient of the gaseous Mo-species $\left(\mathrm{Mo}_{2} \mathrm{O}_{5}\left(\mathrm{OCH}_{3}\right)_{2}\right)$ and water is estimated using Chapman-Enskog theory for diffusion, using the $\mathrm{MeOH}$ as reference species:

$$
D_{e, i}^{0}=D_{e, \mathrm{MeOH}}^{0} \frac{\sqrt{1 / M_{g a s}+1 / M_{i}}}{\sqrt{1 / M_{g a s}+1 / M_{M e O H}}}
$$

Where $D_{e, i}^{0}$ is the effective diffusion coefficient $\left(\mathrm{m}^{2} / \mathrm{s}\right)$ and $M_{i}$ is the molar weight $(\mathrm{g} / \mathrm{mol})$ of component $i$.

$M_{\mathrm{MeOH}}$ and $M_{\text {gas }}$ is the molar weight of $\mathrm{MeOH}$ and the entire gas $(\mathrm{g} / \mathrm{mol})$ respectively. 


\subsection{Solution procedure}

Before the system of equations was solved, it was made dimensionless (S8-S24). The partial differential equation system was transformed to ordinary differential equations by discretization in the pellet radial dimension using a central finite difference scheme and solved using the method of lines (MoL) with the build-in Matlab solver ODE15s.

The activity of the solid $\mathrm{MoO}_{3}\left(a_{\mathrm{MoO}_{3}}\right.$ see equation (6)-(7)) is equal to 1 if there is solid $\mathrm{MoO}_{3}$ present and 0 if all $\mathrm{MoO}_{3}$ has volatilized. This step changes makes the system very stiff and difficult to solve numerically. To make the system less stiff the activity is replaced by the following expression:

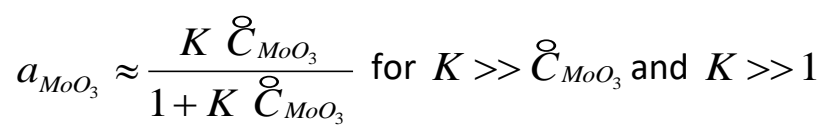

While $\mathrm{MoO}_{3}$ is present, the expression will be close to zero order behavior. However, when the concentration of $\mathrm{MoO}_{3}$ approaches 0 the expression will change to first order behavior. By replacing the activity by this expression the system becomes less stiff. 


\subsubsection{Estimation of pellet mass loss}

The model predicts the excess $\mathrm{MoO}_{3}$ profile through the radial direction of the pellet. The profile is converted to the remaining excess $\mathrm{MoO}_{3}$ in the pellet, by taking the cylindrical geometry of the radial plane into account as follows:

$$
\text { Excess } \mathrm{MoO}_{3}=\int_{R_{h}}^{R_{p}} C_{\mathrm{MoO}_{3}}(r) \frac{r}{R_{p}^{2}-R_{h}^{2}} d r
$$

Where $C_{\mathrm{MoO}_{3}}(r)$ is the predicted concentration of excess $\mathrm{MoO}_{3}$ at the position $r$ and $R_{p}$ and $R_{h}$ are the outer and inner radius respectively of the pellet.

Furthermore, for comparison of the model results with the experimental data, the depletion layer thickness at the top of the pellet was assumed to be equal to the thickness in the radial plane.

\subsection{Fitting procedure}

The model predicts the profiles through the catalyst pellet of the various species and the total loss of excess $\mathrm{MoO}_{3}$ from the pellet. The total Mo loss can simply be converted to the corresponding mass loss. The model is fitted towards the measured mass loss data shown in Figure 6-Figure 8 indicating a good fit to the data. The parameters to be fitted in the model are the reaction orders, rate constants of the rate expressions (4)-(7) and the adsorption equilibrium constant $\left(K_{3}\right)$ with respect to water (6)-(7).

The backwards volatilization rate constant $\left(k^{-}\right)$, is fitted using a modified Arrhenius equation as follows: 


$$
k^{-}(T)=k^{-}\left(T_{R e f}\right) \cdot \exp \left(\frac{-E_{a}^{-}}{R} \cdot\left(\frac{1}{T}-\frac{1}{T_{R e f}}\right)\right)
$$

Where $k^{-}\left(T_{R e f}\right)$ is the backwards rate constant at a reference temperature $\left(300^{\circ} \mathrm{C}\right)$. By introducing a reference temperature the correlation between the pre-exponential factor and the activation energy is significantly decreased [23]. Due to the limited amount of data the water quilibrium constant is assumed independent of temperature.

The backwards volatilization rate constant at the reference temperature $\left(k^{-}\left(T_{R e f}\right)\right)$, the activation energy $\left(E_{a}^{-}\right.$ ), the reaction orders and waters adsorption equilibrium constant ( $\left.K_{3}\right)$ are fitted to the mass loss data using the built-in MATLAB optimization tool fmincon. The fitted parameters are used in the built-in MATLAB statistic tool nlinfit, which provide the statistics used to calculate the $95 \%$ confidence intervals of the fitted parameters (Table 2), the covariance matrix and the Pearson's correlation coefficients (Table S4 and Table S5). The correlation between the model parameters is low $(<29 \%)$, which indicate that all the parameters are relevant for the model.

The rate constants with respect to the main reaction $\left(k_{\mathrm{MeOH}}, k_{1}\right.$ and $\left.k_{2}\right)$ were fitted to methanol conversion data not enclosed here. Popov et al. [4] studied the volatilization of Mo from the iron molybdate catalyst, and reported a rate constant of Mo volatilization of $4.4 \times 10^{-3} \mathrm{~s}^{-1}$ at low contact time $(<0.005 \mathrm{~s})$. This value was fixed and used independently of temperature. The backward volatilization rates were fitted independently for the different temperatures towards the mass loss of the pellets. The fitted constants and the forward volatilization rate constant are shown in Table 2 . Since the forward volatilization rate constant, $k^{+}$, is kept constant at all temperatures, the activation energy $\left(E_{a}^{-}\right)$of the backward rate constant $\left(k^{-}(T)\right)$ is negative, yielding faster overall volatilization at increased temperature. 
Table 2 - Fitted reaction orders and rate constants (95\% confidence intervals) for the single pellet model (Table 1).

\begin{tabular}{l}
\hline \multicolumn{1}{c}{ Rate constants } \\
\hline$n_{M e O H}=1.50 \pm 0.02$ \\
$n_{M o(g)}=1.00 \pm 0.01$ \\
$K_{3}=64.89 \pm 0.91$ \\
$k_{+}=4.4 \cdot 10^{-3}\left[s^{-1}\right][4]$ \\
$E_{a}^{-}=-45.7 \pm 0.7\left[\frac{k J}{m o l}\right]$ \\
$k^{-}\left(T_{R e f}\right)=(1.47 \pm 0.018) \cdot 10^{6}\left[s^{-1}\right]$ \\
\hline
\end{tabular}




\subsection{Model predictions}

\subsubsection{Excess $\mathrm{MoO}_{3}$ profile}

Figure 11 shows the model predictions of the radial excess $\mathrm{MoO}_{3}$ profiles and the measured depletion layer thickness for a representative section of the depleted pellets investigated by SEM-EDS (Figure 2 and Figure 4) and X-ray $\mu$-CT (Figure 9). The model is only fitted towards the mass loss measurements, and so the corresponding prediction of the Mo profiles through the pellets can be used as independent validation of the models capability to predict the Mo depletion behavior. The model predicts the thickness of the depletion layer well and correctly predicts the deposition behavior of $\mathrm{MoO}_{3}$ inside the pellet at high temperature and no $\mathrm{H}_{2} \mathrm{O}$ in the feed $\left(350^{\circ} \mathrm{C}, \mathrm{MeOH}=4.4 \%, \mathrm{H}_{2} \mathrm{O}=0 \%, \mathrm{O}_{2}=10 \%\right.$ in $\left.\mathrm{N}_{2}\right)$. With respect to the depleted pellet investigated by $\mu-C T$, the depletion of the entire pellet was estimated to 20.3 vol.\% by segmentation, which corresponds to a predicted depletion layer at a distance equal to 0.85 . The depletion layer thickness measured with $\mu$-CT is in good agreement with the model prediction (0.86).

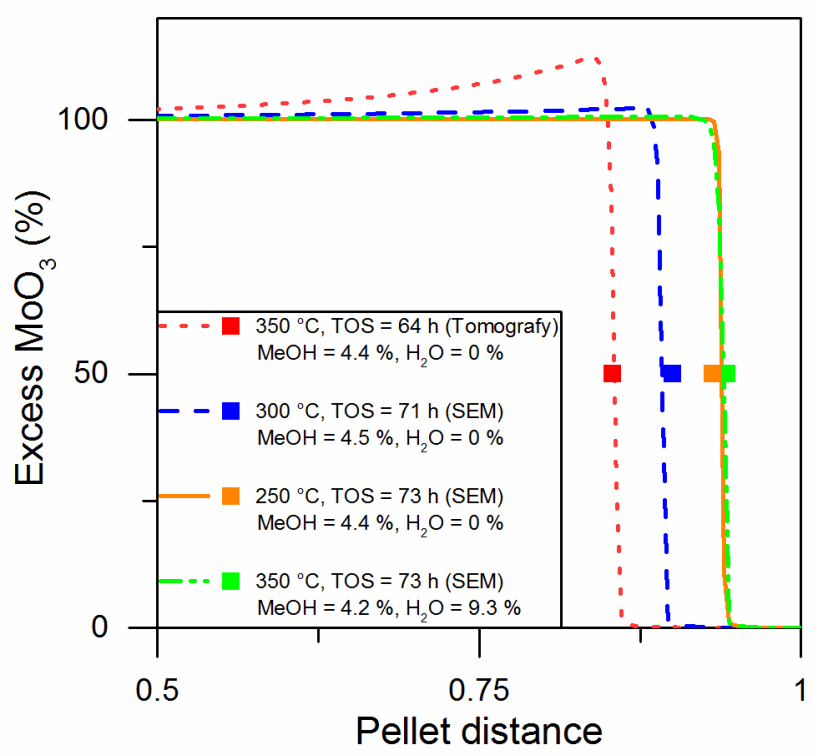

Figure 11 - Model prediction of $\mathrm{MoO}_{3}$ profile (lines) and depletion layer thickness (squares) across the radial direction of the pellet. Pellet distance $=0$ is equal to the inner surface and pellet distance $=1$ is equal to outer surface. Initial $\mathrm{Mo} / \mathrm{Fe}=2.4 . \mathrm{O}_{2}=10 \%$ and $\mathrm{N}_{2}$ as balance. 


\subsubsection{MeOH, $\mathrm{Mo}(\mathrm{g}), \mathrm{H}_{2} \mathrm{O}$ and porosity profiles}

For the representative section of pellets shown in Figure 11, the $\mathrm{MeOH}, \mathrm{Mo}(\mathrm{g}), \mathrm{H}_{2} \mathrm{O}$ and porosity profiles are shown in Figure 12. For all gasous species the concentration is equal to the feed concentration at the pellet surface (pellet distance $=1$ ) due to the assumption of no gas film resistance. $\mathrm{MeOH}$ is converted through the pellet forming formaldehyde along with $\mathrm{H}_{2} \mathrm{O}$. As expected high bulk $\mathrm{H}_{2} \mathrm{O}$ concentration $(9.3 \%)$ inhibits the $\mathrm{MeOH}$ conversion (compare red and green curves at $350 \mathrm{C}$ ). The volatile Mo species (Mo(g)) are formed by $\mathrm{MeOH}$ and solid excess $\mathrm{MoO}_{3}$ in the pellet. At the inside of the depletion front the Mo species follows the trend of $\mathrm{MeOH}$. However, outside the front there is no excess $\mathrm{MoO}_{3}$ to form the Mo species. The concentration of Mo species decreases from a maximum at the front to zero (the imposed bulk concentration) through the depleted layer. Also note that the concentration of the volatile Mo species is 12 orders of magnitude lower than the $\mathrm{MeOH}$ concentration. Despite this low value, it is enough to remove significant levels of $\mathrm{MoO}_{3}$ with time. The porosity increases as the pellet is depleted of excess $\mathrm{MoO}_{3}$, and likewise decreases when $\mathrm{MoO}_{3}$ is deposited inside the pellet. 

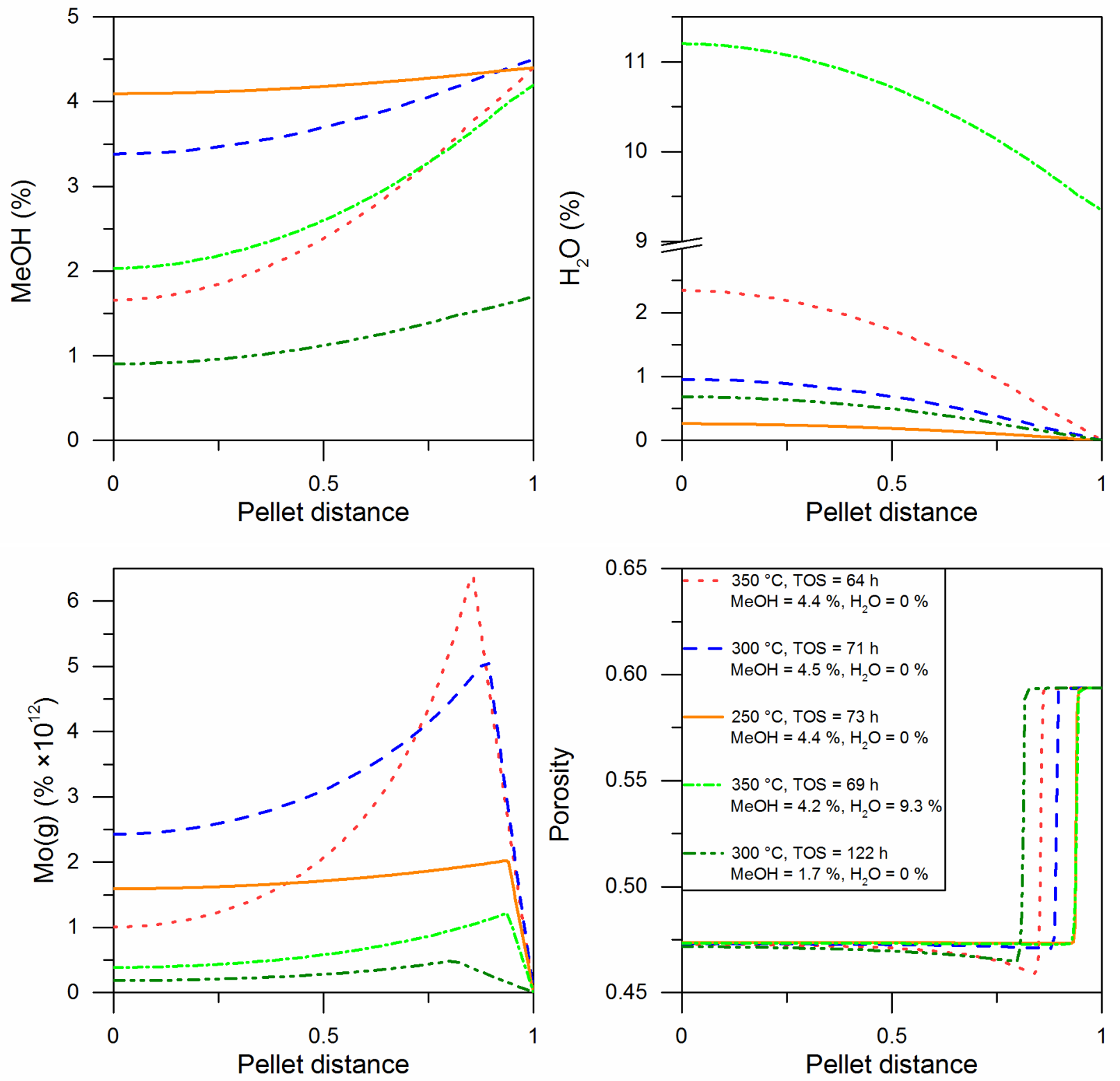

Figure 12 - Model prediction of $\mathrm{MeOH}$, volatile $\mathrm{Mo}$ species $(\mathrm{Mo}(\mathrm{g})), \mathrm{H}_{2} \mathrm{O}$ and the porosity profiles across the radial direction of the pellet. Pellet distance $=0$ is equal to the inner surface and pellet distance $=1$ is equal to outer surface. Initial $\mathrm{Mo} / \mathrm{Fe}=2.4$. The legend is the same for all figures. 


\subsubsection{Loss of excess $\mathrm{MoO}_{3}$}

The model is capable of predicting the corresponding loss of excess $\mathrm{MoO}_{3}$ at varying reaction conditions with time on stream with reasonable accuracy (Figure 6-Figure 8). The equilibrium of the volatilization reaction (2) is shifted towards the volatile Mo species and the loss of excess $\mathrm{MoO}_{3}$ in the pellet with increasing temperature (Figure 7). At a temperature of $350{ }^{\circ} \mathrm{C}$ and TOS above $159 \mathrm{~h}$ formation of $\mathrm{FeMoO}_{4}$ in the depletion layer takes place, which the model does not take into account, hence the underestimation of the excess $\mathrm{MoO}_{3}$ loss. Water inhibits the forward volatilization reaction which in turn decreases the volatilization rate with increasing water concentration (Figure 6). However, the forward volatilization reaction is enhanced by the $\mathrm{MeOH}$ concentration and the rate of volatilization increases with increasing $\mathrm{MeOH}$ concentration (Figure 6).

To further verify the model, two additional sets of data were generated (Figure 13 and Figure 14) at varying temperature and other reaction conditions $\left(\mathrm{MeOH}=\sim 2 \%, \mathrm{H}_{2} \mathrm{O}=0 \%\right.$ and $\mathrm{MeOH}=\sim 4 \%, \mathrm{H}_{2} \mathrm{O}=\sim 10 \%$, both at $\mathrm{O}_{2}=10 \%$, in $\mathrm{N}_{2}$ ). At low $\mathrm{MeOH}$ concentration (1.6-1.7\% MeOH (Figure 13)) the model slightly over predicts the loss of $\mathrm{MoO}_{3}$. At high $\mathrm{H}_{2} \mathrm{O}$ concentration (9.4-10.2 \% $\mathrm{H}_{2} \mathrm{O}$ (Figure 14)) the model prediction is rather accurate at 250 and $300{ }^{\circ} \mathrm{C}$. However, at $350{ }^{\circ} \mathrm{C}$ the model slightly under predicts the loss of $\mathrm{MoO}_{3}$. The inaccurate prediction at low $\mathrm{MeOH}$ concentration indicates that there is an effect in the volatilization of $\mathrm{MoO}_{3}$ that the model does not account for. Furthermore, the inaccurate predictions at $350{ }^{\circ} \mathrm{C}$ indicate that there is likely a temperature dependency of the inhibiting effect of water $\left(K_{3}\right)$ on the volatilization of $\mathrm{MoO}_{3}$, which is not taken into account in the model due to the limited amount of data. Measuring a larger amount of data and including this temperature effect in the model is expected to improve the accuracy of the model at all temperatures. 


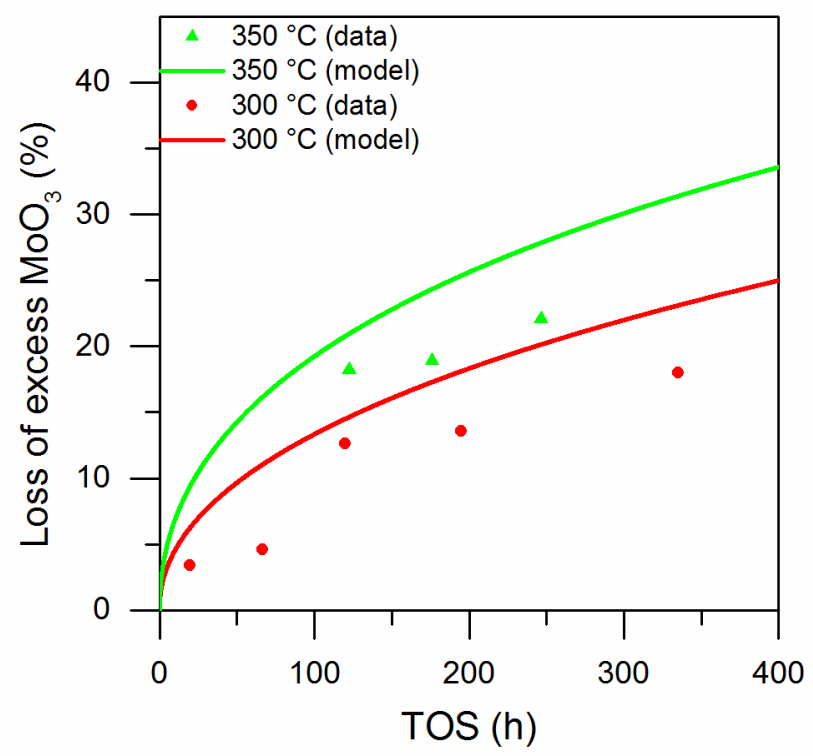

Figure 13 - Mass loss of excess $\mathrm{MoO}_{3}$ in pellets at increasing TOS. Treated at $\mathrm{MeOH}=1.6-1.7 \%, \mathrm{H}_{2} \mathrm{O}=0 \%, \mathrm{O}_{2}=10 \%$ in $\mathrm{N}_{2}$ at 300 $350^{\circ} \mathrm{C}$. Mo/Fe $=2.4$. Flow rate $=3000 \mathrm{~mL} / \mathrm{min}(1 \mathrm{bar}, 273.15 \mathrm{~K})$.

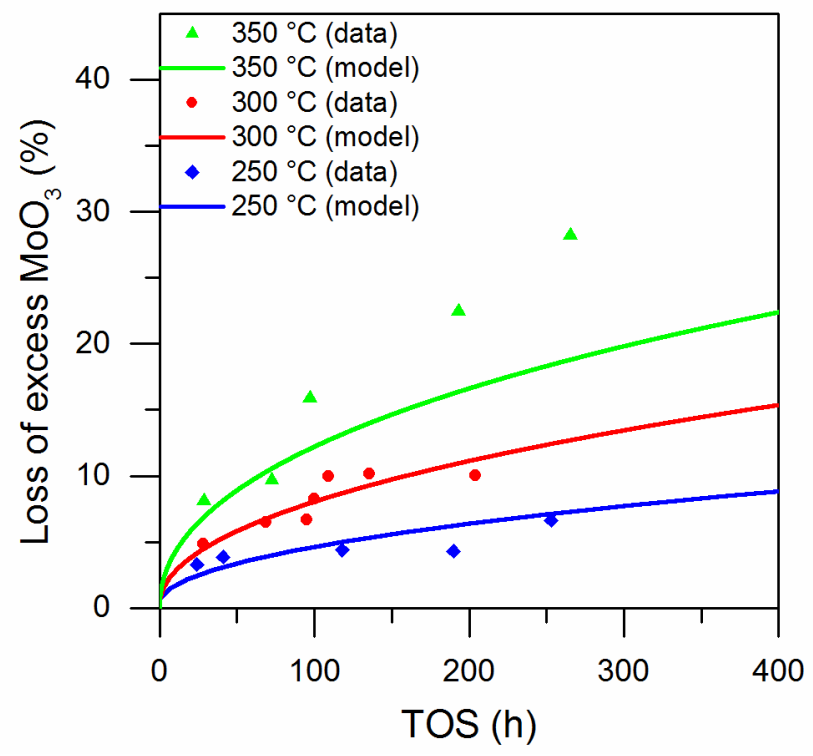

Figure 14 - Mass loss of excess $\mathrm{MoO}_{3}$ in pellets at increasing TOS. $\mathrm{MeOH}=3.6-4.2 \%, \mathrm{H}_{2} \mathrm{O}=9.4-10.2 \%, \mathrm{O}_{2}=10 \%$ in $\mathrm{N}_{2}$ at $250-350^{\circ} \mathrm{C}$. $\mathrm{Mo} / \mathrm{Fe}=2.4$. Flow rate $=3000 \mathrm{~mL} / \mathrm{min}(1 \mathrm{bar}, 273.15 \mathrm{~K})$. 
Figure 15 shows a comparison of the measured and predicted mass loss for the applied reaction conditions.

$90 \%$ of the predictions are within $7 \%$ of the measurements, which confirms that the model predictions are in good agreement with the measured data. The two data points in Figure 7 where $\mathrm{FeMoO}_{4}$ were formed are not included.

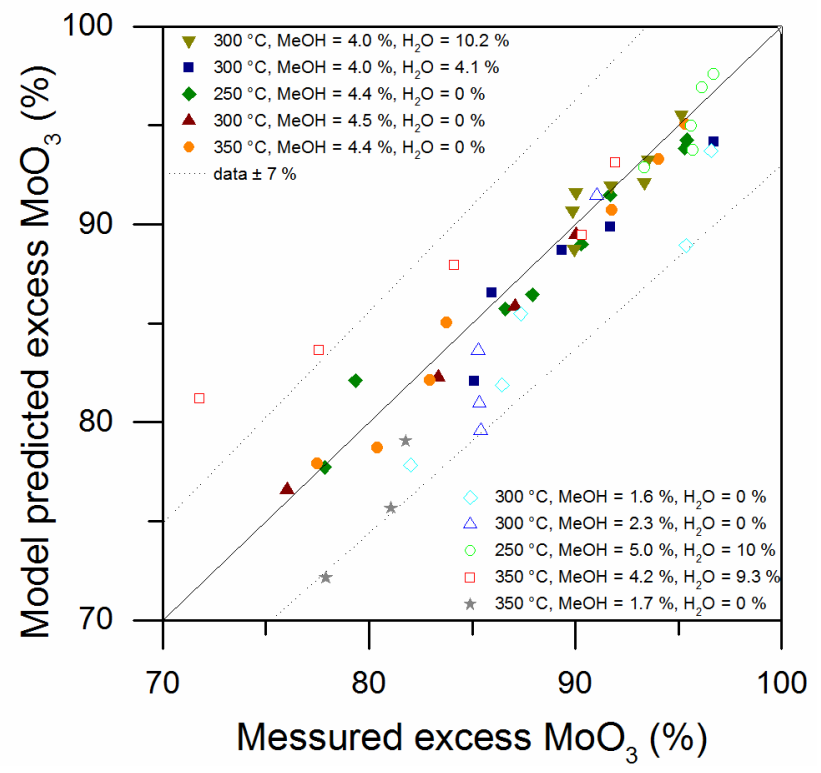

Figure 15 - Comparison of predicted vs measured excess $\mathrm{MoO}_{3}$ in pellet.

\section{Discussion}

\subsection{Effect of catalyst pellet size}

As reported by the authors [17], excess $\mathrm{MoO}_{3}$ volatizes completely from small catalyst particles within hours (TOS $=10 \mathrm{~h}$, sieve fraction 150-250 nm, initial Mo/Fe = 2). However, in the current work Mo volatilization from catalyst pellets is significantly slower. The significant difference in the overall rate of Mo volatilization is mainly due to the difference in the size between the small particles and the catalyst pellets. For the small catalyst particles the depletion layer only has to develop a small distance to reach the center of the particle and completely volatilize all excess $\mathrm{MoO}_{3}$. However, for the larger pellets the depletion layer must develop a larger 
distance through the pellet, and the time to completely volatilize all $\mathrm{MoO}_{3}$ in the pellet will be significantly higher.

To demonstrate the effect of the catalyst pellet size, the model has been used calculate the loss of excess $\mathrm{MoO}_{3}$ at varying pellet size $\left(\mathrm{MeOH}=5 \%, \mathrm{H}_{2} \mathrm{O}=5 \%\right.$ at $\left.300{ }^{\circ} \mathrm{C}\right)$. The pellets size has been scaled with respect to volume keeping the ratio between the dimensions constant (pellet length, inner and outer radius). The loss of excess Mo can be seen in Figure 16. The pellet size affects the overall depletion of Mo and by increasing the pellet volume to $200 \%$ the depletion is decreased from 21.5 to $17.2 \%$ after $400 \mathrm{~h}$ on stream (corresponding to a decrease of $20 \%)$.

However, increasing the pellet size might lead to other process challenges, such as difficult packing of the catalyst in the reactor tubes and non-intended high temperatures in the pellet center. Furthermore, the overall process selectivity might be affected, due to higher formaldehyde concentration inside larger pellets leading to increased oxidation of formaldehyde to $\mathrm{CO}$ [24].

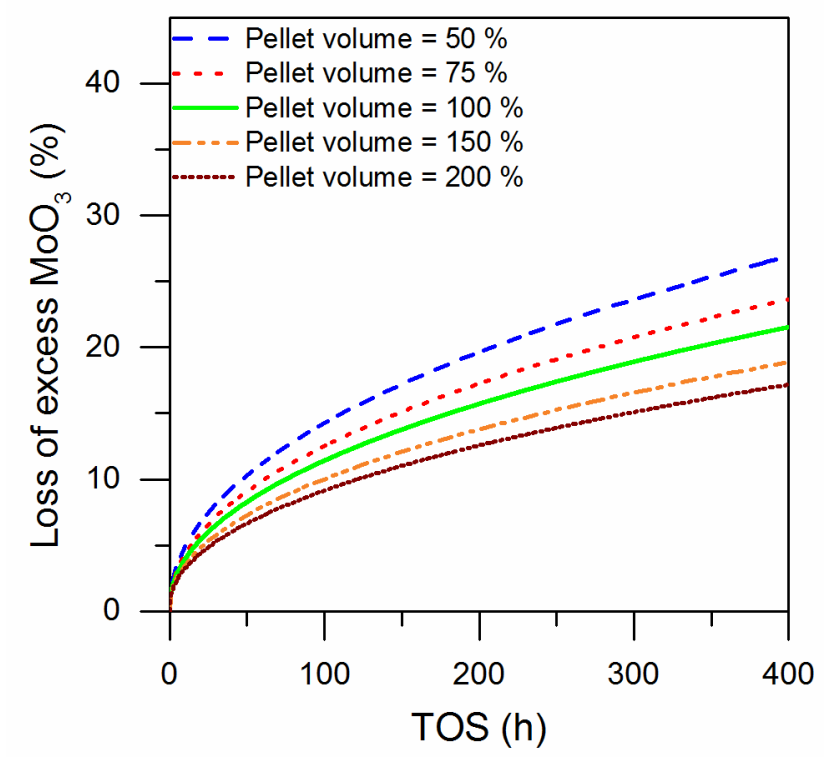

Figure 16 - Predicted mass loss of excess $\mathrm{MoO}_{3}$ in pellets at increasing TOS. The ratios of the pellet dimensions are constant (pellet length, inner and outer radius). $\mathrm{MeOH}=5 \%, \mathrm{H}_{2} \mathrm{O}=5 \%$ at $300^{\circ} \mathrm{C}$. Initial $\mathrm{Mo} / \mathrm{Fe}=2.4$. 


\section{Conclusion}

The influence of temperature and concentration of methanol and water on the molybdenum loss from iron molybdate catalyst pellets $\left(\mathrm{Fe}_{2}\left(\mathrm{MoO}_{4}\right)_{3}\right.$ with excess $\mathrm{MoO}_{3}$ corresponding to a molar Mo/Fe ratio of 2.4) used in the oxidation of methanol to formaldehyde was investigated experimentally. The volatilization and diffusion of molybdenum, leads to a layer depleted of excess $\mathrm{MoO}_{3}$ evolving from the surface of the catalyst pellet. The rate of depletion is increased by $\mathrm{MeOH}$ and temperature, due to the volatilization reaction between $\mathrm{MeOH}$ and solid $\mathrm{MoO}_{3}$ in the catalyst. Water in the gas phase inhibits the volatilization reaction and the rate of depletion. A 1D dynamic single particle model was furthermore developed and compared to experimental data. The model simultaneously calculates the formation of formaldehyde in the pellet, the volatilization of Mo and subsequent transport of the volatile Mo species into and out of the pellet as function of time. The model parameters were fitted to the overall mass loss of the pellets at varying reaction conditions and time on stream, using a feed composition of 1.6-4.5 \% MeOH, 0-10.2\% $\mathrm{H}_{2} \mathrm{O}, 10 \% \mathrm{O}_{2}$ balance $\mathrm{N}_{2}$ at $250-350{ }^{\circ} \mathrm{C}$. The model is capable of describing the molybdenum loss and corresponding depletion layer thickness of a single catalyst pellet. The model shows a significant effect of pellet size on the overall rate of $\mathrm{MoO}_{3}$ volatilization and the use of pellets in the industrial process is required to dampen the loss of Mo. Incorporation of the single pellet model into a reactor model could be a useful tool to predict the loss of Mo and the associated pressure drop development in a reactor and estimation of process lifetime at varying reaction conditions and is ongoing in our group. 


\section{Acknowledgments}

This work is a collaboration between the CHEC research center at The Department of Chemical and Biochemical Engineering at Technical University of Denmark (DTU) and Haldor Topsøe A/S. We thank the Independent Research Fund Denmark for the financial support (DFF - 4184-00336). The 3D Imaging Centre at the Technical University of Denmark is also gratefully acknowledged for their valuable support on X-ray computed tomography acquisition and image processing.

\section{Supplementary data}

Detailed model derivation, SEM images and pellet mass loss data with corresponding model predictions.

\section{References}

[1] H. Adkins and W. Peterson, "The oxidation of methanol with air over iron, molybdenum, and ironmolybdenum oxides," J. Am. Chem. Soc., vol. 53, no. 1927, pp. 1512-1520, 1931.

[2] R. Günther, W. Disteldorf, A. O. Gamer, and A. Hilt, "Ullmann's encyclopedia of industrial chemistry," Weinheim, vol. Chapter 4, p. Chapter 4, 2012.

[3] N. Burriesci, F. Garbassi, M. Petrera, G. Petrini, and N. Pernicone, "Solid State Reactions in Fe-Mo Oxide Catalysts for Methanol Oxidation During Aging in Industrial Plants.," Stud. Surf. Sci. Catal., vol. 6, pp. 115-126, 1980.

[4] B. I. Popov, V. N. Bibin, and G. K. Boreskov, "Study of an iron-molybfate oxide catalyst for oxidation of methanol to formaldehyde," Kinet. Catal., vol. 17, no. 2, pp. 322-327, 1976.

[5] A. Andersson, M. Hernelind, and O. Augustsson, "A study of the ageing and deactivation phenomena 
occurring during operation of an iron molybdate catalyst in formaldehyde production," Catal. Today, vol. 112, pp. 40-44, 2006.

[6] B. R. Yeo, G. J. F. Pudge, K. G. Bugler, A. V. Rushby, S. Kondrat, J. Bartley, S. Golunski, S. H. Taylor, E. Gibson, P. P. Wells, C. Brookes, M. Bowker, and G. J. Hutchings, "The surface of iron molybdate catalysts used for the selective oxidation of methanol," Surf. Sci., vol. 648, pp. 163-169, 2016.

[7] C. Brookes, P. P. Wells, N. Dimitratos, W. Jones, E. K. Gibson, D. J. Morgan, G. Cibin, C. Nicklin, D. MoraFonz, D. O. Scanlon, C. R. A. Catlow, and M. Bowker, "The Nature of the Molybdenum Surface in Iron Molybdate. The Active Phase in Selective Methanol Oxidation," J. Phys. Chem. C, vol. 118, no. 45, pp. 26155-26161, 2014.

[8] J. M. Tatibouët, "Methanol oxidation as a catalytic surface probe," Appl. Catal. A Gen., vol. 148, pp. 213-252, 1997.

[9] W. H. Cheng, "Methanol and formaldehyde oxidation study over molybdenum oxide," J. Catal., vol. 158, no. 2, pp. 477-485, 1996.

[10] J. S. Chung, R. Miranda, and C. O. Bennett, "Mechanism of Partial Oxidation of Methanol over MoO3," J. Catal., vol. 114, pp. 398-410, 1988.

[11] B. I. Popov and N. G. Skomorokhova, "Changes in activity, selectivity and surface area along an ironmolybdenum catalyst bed after its industrial application," React. Kinet. Catal. Lett., vol. 18, no. 1-2, pp. 101-105, 1982.

[12] K. I. Ivanov and D. Y. Dimitrov, "Deactivation of an industrial iron-molybdate catalyst for methanol oxidation," Catal. Today, vol. 154, no. 3-4, pp. 250-255, 2010.

[13] Y. H. Ma and S. J. Kmiotek, “Deactivation Kinetics of Ferric Molybdate," vol. 142, pp. 132-142, 1988.

[14] M. P. House, A. F. Carley, and M. Bowker, "Selective oxidation of methanol on iron molybdate catalysts and the effects of surface reduction," J. Catal., vol. 252, pp. 88-96, 2007.

[15] I. Mitov, S. Asenov, T. Tomov, and D. Klissurski, "In situ Mössbauer Study of the Interaction of Methanol with An Iron-Molybdenum Oxide Catalyst," J. Phys. Chem. C, vol. 111, no. 14, pp. 5389-5393, 2007. 
[16] N. Pernicone, "Deactivation of Fe-Mo Oxide Catalyst in Industrial Plant and Simulation Tests on Laboratory Scale," Catal. Today, vol. 11, pp. 85-91, 1991.

[17] K. V. Raun, L. F. Lundegaard, J. Chevallier, P. Beato, C. C. Appel, K. Nielsen, M. Thorhauge, A. D. Jensen, and $\mathrm{M} . \mathrm{H} \varnothing \mathrm{j}$, "Deactivation behavior of an iron-molybdate catalyst during selective oxidation of methanol to formaldehyde," Catal. Sci. Technol., vol. 8, no. 18, pp. 4626-4637, 2018.

[18] R. L. Smith and G. S. Rohrer, "The Morphological Evolution of the MoO3 ( 010 ) Surface during Reactions in Methanol - Air Mixtures," vol. 278, pp. 270-278, 1998.

[19] T. Ressler, J. Wienold, R. E. Jentoft, and T. Neisius, "Bulk structural investigation of the reduction of MoO3with propene and the oxidation of MoO2with oxygen," J. Catal., vol. 210, no. 1, pp. 67-83, 2002.

[20] M. P. House, A. F. Carley, R. Echeverria-Valda, and M. Bowker, "Effect of varying the cation ratio within iron molybdate catalysts for the selectivev oxidation of methanol," J. Phys. Chem. C, vol. 112, no. 11, pp. 4333-4341, 2008.

[21] S. a R. K. Deshmukh, M. Van Sint Annaland, and J. a M. Kuipers, "Kinetics of the partial oxidation of methanol over a Fe-Mo catalyst," Appl. Catal. A Gen., vol. 289, no. 2, pp. 240-255, 2005.

[22] V. N. Bibin and B. I. Popov, "Kinetics of Methanol Oxidation by Air on Iron-Molybdenum Oxide Catalysts," Kinet. Catal. (Engl. Transl.), vol. 10, no. 6, pp. 1091-1098, 1969.

[23] J. B. Rawlings and J. G. Ekerdt, Chemical reactor analysis and desing fundamentals. Nob Hill Publishing, 2002.

[24] Anthony G. Dixon, "Integrated Multiscale Modeling of Fixed Bed Reactors: Studying the Reactor under Dynamic Reaction Conditions," in Florence (ISCRE25), 2018. 